IZA DP No. 8390

The Effects of Paid Family Leave in California on Labor Market Outcomes

Charles L. Baum

Christopher J. Ruhm

August 2014 


\title{
The Effects of Paid Family Leave in California on Labor Market Outcomes
}

\author{
Charles L. Baum \\ Middle Tennessee State University \\ Christopher J. Ruhm \\ University of Virginia, \\ NBER and IZA
}

Discussion Paper No. 8390

August 2014

IZA
P.O. Box 7240
53072 Bonn
Germany

Phone: +49-228-3894-0

Fax: +49-228-3894-180

E-mail: iza@iza.org

\begin{abstract}
Any opinions expressed here are those of the author(s) and not those of IZA. Research published in this series may include views on policy, but the institute itself takes no institutional policy positions. The IZA research network is committed to the IZA Guiding Principles of Research Integrity.

The Institute for the Study of Labor (IZA) in Bonn is a local and virtual international research center and a place of communication between science, politics and business. IZA is an independent nonprofit organization supported by Deutsche Post Foundation. The center is associated with the University of Bonn and offers a stimulating research environment through its international network, workshops and conferences, data service, project support, research visits and doctoral program. IZA engages in (i) original and internationally competitive research in all fields of labor economics, (ii) development of policy concepts, and (iii) dissemination of research results and concepts to the interested public.
\end{abstract}

IZA Discussion Papers often represent preliminary work and are circulated to encourage discussion. Citation of such a paper should account for its provisional character. A revised version may be available directly from the author. 
IZA Discussion Paper No. 8390

August 2014

\section{ABSTRACT}

\section{The Effects of Paid Family Leave in California on Labor Market Outcomes}

Using data from the 1997 cohort of the National Longitudinal Survey of Youth (NLSY-97), we examine the effects of California's paid family leave program (CA-PFL) on mothers' and fathers' use of leave during the period surrounding child birth, and on the timing of mothers' return to work, the probability of eventually returning to pre-childbirth jobs, and subsequent labor market outcomes. Our results show that CA-PFL raised leave-taking by around three weeks for the average mother and approximately one week for the average father. The timing of the increased leave use - immediately after birth for men and around the time that temporary disability insurance benefits are exhausted for women - is consistent with causal effects of CA-PFL. Rights to paid leave are also associated with higher work and employment probabilities for mothers nine to twelve months after birth, possibly because they increase job continuity among those with relatively weak labor force attachments. We also find positive effects of California's program on hours and weeks of work during their child's second year of life and possibly also on wages.

JEL Classification: J1, J2, J3, J13, J18

Keywords: parental leave, paid leave, family leave, employment, wages, leave-taking, return-to-work decisions

Corresponding author:

Christopher J. Ruhm

Frank Batten School of Leadership and Public Policy

University of Virginia

204 Garrett Hall, 235 McCormick Rd.

P.O. Box 400893

Charlottesville, VA 22904-4893

USA

E-mail: ruhm@virginia.edu 


\section{Introduction}

Most industrialized countries provide new mothers (and sometimes fathers) rights to a substantial amount of paid leave following the birth of a child. For example, German mothers may take up to a year off from work while receiving 67 percent of their usual pay, and Canada supplies a year or more of maternity leave with 55 percent of pay replaced. Conversely, the United States is one of only four nations without entitlements to paid leave (Heymann, Earle, and Hayes, 2007).

Prior to the 1993 Family and Medical Leave Act (FMLA), the U.S. did not provide federal rights to unpaid leave either. ${ }^{1}$ However, just as some states passed their own laws granting unpaid maternity leave before the FMLA, states have begun to provide paid family leave $(P F L)$ from work to care for a newborn or a sick child, spouse, or parent. California was the first state to do so, approving six weeks of PFL with 55 percent of usual pay replaced (up to \$1,075 per week in 2014), although this leave is not job-protected and is typically not provided to public-sector employees. ${ }^{2}$

California’s paid family leave statute (CA-PFL), which was passed in 2002 and took effect July 1, 2004, is financed through a payroll tax levied on employees and was added to the pre-

${ }^{1}$ The FMLA provides for 12 weeks of unpaid leave following the birth or adoption of a child, with exemptions for small firms and employees not meeting a work history requirement. The law also covers time off work due to their own or a family member's serious health problem, and so is called “family leave” rather than "parental leave.” Along this dimension, the FMLA and the state laws we discuss below are broader than the provisions in many other countries. See Ruhm (2011) for a detailed discussion of family and parental leave laws in both a U.S. and an international context.

${ }^{2}$ Information on California's paid leave program in this and the next paragraph is obtained from Fass (2009); Applebaum and Milkman (2011) and Employment Development Department (2014). 
existing Temporary Disability Insurance program that typically provides mothers with six weeks of paid leave during or just after pregnancy. In July 2009, New Jersey began a "family leave insurance” program quite similar to CA-PFL, also added to the state's TDI system, which offers six weeks of paid leave at a 66 percent replacement rate, although with a considerably lower (\$595 per week in 2014) maximum benefit (Department of Labor and Workforce Development, 2014). Beginning in 2014, Rhode Island's “temporary caregiver's insurance” program will provide four weeks of paid leave at a 60 percent wage replacement rate, up to a ceiling (\$752 per week in 2014). As with California and New Jersey, the program is coordinated with the state's temporary disability insurance; however, job protection is also provided during the leave period. ${ }^{3}$ Washington state approved $\$ 250$ per week in paid benefits to be provided for five weeks, with the program scheduled to begin in 2009 (Progressive States Network, 2010); however, due to budgetary pressures, implementation has been repeatedly postponed and is now not scheduled until 2015 (Employment Security Department, 2013). ${ }^{4}$ In addition, President Obama proposed (unsuccessfully) in his 2011

${ }^{3}$ Information on the Rhode Island program is available at www.dlt.ri.gov/tdi/tdifaqs.htm and www.shrm.org/LegalIssues/StateandLocalResources/Pages/Rhode-Island-Temporary-Caregiver-

\section{Leave.aspx.}

${ }^{4}$ Unlike California and New Jersey, Washington does not have a temporary disability system upon which paid family leave could be added. Only three other states - Hawaii, New York, and Rhode Island - have temporary disability insurance programs (Fass, 2009) and the TDI benefits are often quite low (e.g. the maximum benefit in New York is $\$ 170$ per week in 2013). 
budget, to allocate $\$ 50$ million in competitive grants to states that start $P F L$ programs and there have been increasing efforts to establish a national paid leave program. ${ }^{5}$

Researchers have previously analyzed the labor market effects of (largely) unpaid family leave in the United States (Klerman and Leibowitz, 1997, 1999; Waldfogel, 1999; Baum, 2003a,b; Han and Waldfogel, 2003; Berger and Waldfogel, 2004; Han, Ruhm, and Waldfogel, 2009) and of paid parental leave in other industrialized countries (Ruhm and Teague, 1997; Albrecht et al., 1998; Ruhm, 1998; Ondrich et al., 1999; Schonberg and Ludsteck, 2007; Baker and Milligan, 2008; Gupta, Smith, and Verner, 2008; Hanratty and Trzcinski, 2009; Lalive and Zweimuller, 2009; Pronzato, 2009). These studies typically examine the effects of the government mandates on aggregate employment rates or wages of mothers or women of childbearing age. ${ }^{6}$ Most of this research suggests that parental leave rights yield positive effects on labor market outcomes, but with some variation in the findings. For example, Ruhm (1998) indicates that short- to medium-length leave

${ }^{5}$ For instance, the Family and Medical Insurance Leave Act, proposed by Sen. Kirsten Gillibrand and Rep. Rosa DeLauro in 2013, would provide workers with 12 weeks of paid leave at a 66 percent wage replacement rate (up to a ceiling), with no employer size exemption, and administered by a new Office of Paid Family and Medical Leave within the Social Security Administration (www.nationalpartnership.org/research-library/work-family/paid-leave/family-act-fact-sheet.pdf).

${ }^{6}$ Parental leave rights could increase aggregate employment and wage levels by preserving employer-employee relationship or reduce them (for at least some groups) by raising labor costs (particularly for the workers most likely to take leave). There is also a related literature examining how parental leave entitlements affect the mental or physical health of children and parents (e.g. Ruhm, 2000; Chatterji and Markowitz, 2005; Tanaka, 2005; Berger et al., 2005; Baker and Milligan, 2010; Rossin, 2011). 
mandates in Europe increase employment without decreasing wages, whereas Lalive and Zweimuller (2009) find that an extension of Austrian paid leave rights from one to two years decreased maternal employment and wages in the short-term but not the long-run.

Paid family leave could have different consequences than the unpaid leave provided under the 1993 FMLA because wage replacement may allow parents facing financial constraints to take more time off work. Moreover, coverage under California PFL is nearly universal, whereas fewer than 60 percent of workers are eligible under the FMLA, due to its firm size and work history requirements. ${ }^{7}$ The effects of the California paid leave program may also depart from those of paid leave in other industrialized nations because of its relatively short duration (e.g., six weeks in California versus a year or more in Canada). ${ }^{8}$

$P F L$ is expected to raise leave-taking in the period immediately following the birth as some parents delay their return to the pre-childbirth job, during which time they are "employed but not at work,” while others take leave rather than quitting their jobs. However, if job continuity is increased, employment and work may rise in the longer-term. These effects will be dampened to the extent that

\footnotetext{
${ }^{7}$ Klerman et al. (2012) estimate that 59 percent of workers were FMLA-eligible in 2012. Eligibility rates will be lower for expectant parents if they work for smaller firms or have less recent employment experience than the average worker.

${ }^{8}$ Benefits in some European countries are long enough to allow parents to have multiple births while on paid leave.
} 
paid leave is available even without the legislation or if the wage replacement rate is too low for parents to afford time off work. ${ }^{9}$

Most closely related to the current research is Rossin-Slater, et al.’s (2013) analysis of March Current Population Survey (CPS) data from 1999-2010. They find that CA-PFL more than doubled the use of maternity leave among mothers with infants - increasing it from three to six or seven weeks for the average mother - and provide suggestive evidence of particularly large growth in use for less advantaged groups and of medium-term increases in the work hours and wages of employed mothers with one to three year old children. However, the March CPS does not identify the precise timing of leave-taking nor permit testing of whether the increases in leave use occur during the period in which $C A-P F L$ is anticipated to have the strongest effects.

We build on the existing literature by using the data from the 1997 cohort of the National Longitudinal Survey of Youth (NLSY-97) to examine how CA-PFL affected leave-taking and (for mothers only) other labor market outcomes. The NLSY-97 provides the location and exact timing of births, as well as detailed work history data before and after it. Our analysis focuses on parents with work experience during the pregnancy period, since this is the group potentially eligible for paid parental leave, and uses a differences-in-differences (DD) approach where the experiences of new California parents in the period after $C A-P F L$ implementation are compared to their counterparts whose children were born earlier, and these changes are contrasted with corresponding parents in comparison states. Specifically, we examine parents' leave and work decisions in each day and week

${ }^{9}$ In 2012, 35 percent of female employees were at worksites offering paid maternity leave (although of potentially short duration) to "all" or "most" employees and 20 percent of males were at sites offering corresponding paternity leave (Klerman, et al., 2012). 
after the child's birth and the likelihood and timing of the return to the pre-birth job, and we consider the experiences of fathers (to the extent the data allow), as well as mothers. ${ }^{10}$

Since the NLSY-97 precisely identifies the timing of births and leave-taking, we are able to determine whether the patterns of leave use are those anticipated by the institutional details of $C A$ $P F L$, making a credible case for causal inference. Specifically, California mothers are expected to begin using PFL following the exhaustion of temporary disability benefits, which typically occurs six to eight weeks after birth, so this is where we should see increases in leave-taking following enactment of the program. Conversely, since fathers do not qualify for (pregnancy-related) TDI benefits, any increase for them should occur immediately after the birth. Examining subsequent employment rates—a year or more after the child's birth—shows longer-term effects of the government leave mandates (e.g. occurring through changes in employer-employee relationships).

Our analysis yields six primary results. First, the availability of $C A-P F L$ increases leavetaking. On average, mothers use around three additional weeks of leave and fathers approximately one extra week. Second, the timing of the rise in leave use - just after the birth for fathers and around the time temporary disability benefits are exhausted for mothers - is consistent with those expected if the program has a causal effect. Third, the increase in maternal leave use primarily reflects work reductions during the first three months after birth, although some specifications also suggest increased rates of employment. Fourth, the California paid leave program is associated with greater probabilities that mothers have returned to work by mothers nine to twelve months after

\footnotetext{
${ }^{10}$ Han et al. (2009) analyzed unpaid leave in the U.S. includes fathers, but they do not know the exact timing of the birth or the reason why parents are employed but not working. Hanratty and Trzcinski (2009) model the return to work after childbirth among Canadian mothers but cannot distinguish between periods of paid and unpaid leave or nonparticipation in the labor force.
} 
giving birth. Fifth, the results for job continuity are mixed, providing little evidence of an increased likelihood that mothers return to their pre-birth employers in our main specifications, but with such a pattern emerging when broadening the sample to include those working fewer weeks during pregnancy. This raises the possibility that $P F L$ provides incentives for some pregnant women to remain on jobs in order to qualify for paid leave benefits (and then subsequently return to the same employer). Last, we find evidence that California's paid leave legislation has positive medium-term effects on weeks and hours worked by mothers and, possibly, also on wages.

\section{Data}

In 1997, the National Longitudinal Survey of Youth began annually collecting information on the labor market experiences and background characteristics of 4,385 females and 4,599 males aged 12 to 16, including oversamples of non-Hispanic blacks and Hispanics. To construct our analysis sample, we selected respondents (mothers and fathers) who had a child between 2000 and 2010 (the last available survey wave) and, in our main specifications, who were employed at least 32 weeks during the nine months before the child's birth. We excluded parents who worked fewer weeks during the pregnancy, since they would be unlikely to qualify for family leave; however, we also test and report on the robustness of the results to this exclusion. ${ }^{11}$ We also omitted the selfemployed who, by definition, do not need to negotiate for leave from work. When weighted, our sample is nationally representative of children born to parents meeting these conditions.

The NLSY-97 collects weekly data on labor market status (i.e. employed, unemployed, outof-the labor force), as well as the exact dates of childbirth. This allowed us to construct a work

\footnotetext{
${ }^{11}$ Parents quitting jobs prior to giving birth will not receive leave benefits. However, some who worked less than 32 weeks during the pregnancy could receive paid leave - e.g. a mother who worked continuously during the second and third but not the first trimester.
} 
history for each new parent identifying whether she or he was employed in each week before and after the birth. The starting and stopping day of paid and unpaid leave spells (during which the individual was employed but not working) are also identified. "Paid leave" refers to paid time off work because of a pregnancy or birth of a child. "Unpaid leave” indicates unpaid vacation or leave that is related to a pregnancy (for spouses in the case of men). One complication is that some respondents may classify time off work provided under $C A-P F L$ as "unpaid leave" because they are not directly paid by their employer, but instead by the State of California. ${ }^{12}$ Therefore, we focus below on the total leave-taking, including both paid and unpaid time off work.

The NLSY-97 questions are designed to capture leaves lasting at least seven days. However, many mothers and fathers report leaves of six or fewer days, and durations of exactly seven days occur only slightly more often than those lasting six or eight days. ${ }^{13}$ For this reason, our analysis proceeds as if all leaves are identified, but we recognize that some short leaves are probably missing. This is likely to be particularly problematic for fathers, who frequently will only be briefly off work. And the restriction should be noted when we consider leave survival probabilities, which will be overstated by the exclusion of some short leaves.

${ }^{12}$ In regression models that separate them, $C A-P F L$ is associated with higher use of both paid and unpaid leave, which is consistent with the hypothesized classification problem, since there is no reason why paid leave would raise unpaid time off work.

${ }^{13}$ For example, $2.0 \%, 3.1 \%, 2.2 \%, 4.1 \%$ and $2.6 \%$ of 2010 year unpaid leaves for female respondents were reported to last four, five, six, seven and eight days respectively. For paid leaves, the corresponding percentages were $1.3 \%, 0.0 \%, 0.9 \%, 1.7 \%, 1.3 \%$. For fathers, these reported percentages were $5.7 \%, 1.3 \%, 1.8 \%, 7.9 \%$, and $3.1 \%$ for unpaid leaves and $11.4 \%, 5.3 \%, 8.3 \%$, 19.7\%, and $14.4 \%$ for paid leaves. 
Mothers are followed for one year after giving birth, in most of the analysis, but the return to work is treated as an absorbing state, so that the tracking is discontinued once this occurs. We are also able to identify the last job held by the mother before her child's birth and the first job after it, and so we can determine whether she returned to the pre-birth employer. Our analysis of fathers is limited to leave-taking - we do not examine future employment probabilities because it seems unlikely that these will be much affected by the brief leaves that (some) fathers take and because any such effects are likely to be overwhelmed, in the differences-in-differences (DD) framework, by small disparities in levels or trends between the treatment and control groups.

The key explanatory factor, $C A-P F L$, is a dummy variable equal to one if the child is born in California on or after July 1, 2004, when the state's paid family leave is in force, and zero for births in other states or in California before that date. $C A-P F L$ is a good indicator of eligibility because coverage is almost universal for private-sector employees. However, some new parents may be ineligible because they stopped working earlier in the pregnancy or do not meet the (weak) work history requirements for coverage. ${ }^{14}$ We also control for the parent's age with a comprehensive set of dummy variables (one for each year of age in the sample), race/ethnicity (black and Hispanic), education (years of school completed), marital status (married vs. unmarried), and years of prior work experience. ${ }^{15}$ Additional covariates include family size, number of biological children, and parity (child birth order).

${ }^{14}$ To be eligible, new parents must have earned at least $\$ 300$ during the 5 to 17 preceding months; there are no other work history or tenure requirements (Applebaum and Milkman, 2011). ${ }^{15}$ We could not further stratify the unmarried group because only $7.2 \%$ of the sample are widowed, separated, or divorced. Work experience is calculated by summing weeks worked, excluding weeks on unpaid or paid leave, through the week preceding the child's birth and then dividing by 52 . 
In supplemental analyses, we explore longer-term effects of CA-PFL on wages and on annual weeks and weekly hours of work. Specifically, we use the NLSY-97 work history data to identify the hourly wage at the mother's job held one year after the birth, as well as the number of hours and weeks worked during the child's second year of life (e.g., the 53rd through 104th weeks after birth). ${ }^{16}$

\section{Empirical Specification}

We use multivariate differences-in-differences (DD) analysis to explore the effects of $C A$ PFL, distinguishing between the impacts on mothers and fathers through the use of separate models for each. Our DD models contrast changes in the outcomes for new California parents before and after enactment of $P F L$ to those for corresponding parents in control states.

The basic DD specification takes the form:

$$
Y_{i c t}=\alpha+\beta_{1} C A_{i c t}+\beta_{2} P O S T_{i c t}+\beta_{3} C A \times P O S T_{i c t}+\gamma_{1} X_{i c t}+\varepsilon_{i c t},
$$

where $Y$ is the outcome, $C A$ is dummy variable taking the value of one for California parents and zero for their control state counterparts, POST is a dichotomous indicator set to one (zero) for births on or after (before) the July 1, 2004 enactment of $P F L, X$ is a vector of supplementary covariates, $\varepsilon$ is an error term, and the subscripts respectively denote parent $i$, child $c$, and $t$ days or weeks after the

\footnotetext{
${ }^{16}$ More precisely, wages are measured at the first job held between the 47th to 57th weeks after birth, adjusted for inflation to year-2012 dollars using the Consumer Price Index (CPI). We also windsorize hourly wages, replacing values below (above) \$5 (\$50) with \$5 (\$50). Windsorizing at other values (e.g., $\$ 1$ and \$100) does not appreciably affect the results. The measures of work weeks and hours do not condition on employment - i.e. they include zero values.
} 
birth. ${ }^{17} \hat{\beta}_{3}$ provides the DD estimate of primary interest. We obtained (but do not show) similar results using the somewhat more flexible model:

$$
Y_{i c t}=\alpha+\beta_{3} C A \times P O S T_{i c t}+\gamma_{1} \boldsymbol{X}_{i c t}+\gamma_{2} \boldsymbol{T}_{i c t}+\gamma_{3} \boldsymbol{S}_{i c t}+\varepsilon_{i c t},
$$

where $\boldsymbol{T}$ and $\boldsymbol{S}$ are vectors of year and state dummy variables. ${ }^{18}$

The outcomes are measures of labor market status including the use of leave before or after birth and, for mothers, the probability of work, employment, and having returned to the pre-birth employer. As mentioned, we restrict the main analysis to parents who worked at least 32 weeks during the pregnancy, since those who have not done so are unlikely to qualify for leave. ${ }^{19}$ The tables also report robust standard errors, clustered at the state level (Bertrand, Duflo, and Mullainathan, 2004).

We present additional results using several variants of (1). In some figures, we show component elements of the DD models through visual comparisons of the outcome variables for California and comparison state parents before and following the implementation of $P F L$, after controlling for demographic characteristics. This is done through estimates of:

$$
Y_{i c t}=\alpha+\beta_{1} C O N T R O L \times P O S T_{i c t}+\beta_{2} C A \times P R E_{i c t}+\beta_{3} C A \times P O S T_{i c t}+\gamma_{1} \boldsymbol{X}_{i c t}+\varepsilon_{i c t},
$$

where CONTROL is a dummy variable equal to one for births from the control states and zero for births from California, and PRE is a dichotomous variable set to one for births before the July 1 , 2004 implementation of PFL. In (2), $\hat{\alpha}$ provides the regression-controlled estimated average value of

${ }^{17}$ Negative values for $t$ indicate periods before the birth.

${ }^{18}\left(1^{\prime}\right)$ controls for a more complete set of time-invariant location-specific effects and for factors that vary uniformly across locations at a point in time. The POST and CA main effects are absorbed by $\boldsymbol{T}$ and $\boldsymbol{S}$, and so do not show up in (1').

${ }^{19}$ This sample inclusion criterion also excludes older women and single men. 
the dependent variable for the reference group of control state parents prior to PFL. Corresponding estimates for control state parents after July 1, 2004 and California parents before and subsequent to PFL implementation are $\hat{\alpha}+\hat{\beta}_{1}, \hat{\alpha}+\hat{\beta}_{2}$, and $\hat{\alpha}+\hat{\beta}_{3}$ respectively.

We also sometimes report parental leave hazard and survival rates for specified periods after birth, estimated using discrete time hazard models (Prentice and Gloeckler,1978; Meyer, 1990, 1995) measuring the probability that a leave spell ends between week (or day) $t$ and $t+1$, conditional on continuing through $t .^{20}$ Hazard models are conceptually appropriate and are well designed to deal with censored observations (e.g., for spells on-going as of the most recently-released wave of data) and the discrete time specification imposes no parametric restrictions on the baseline hazard function.

Defining $\lambda_{i c}(t)$ as the hazard rate $t$ weeks (or days) after the birth of child $c$ for parent $i$,

$$
\lambda_{i c}(t)=\operatorname{prob}\left[t+1 \geq T_{i c} \mid T_{i c} \geq t\right]
$$

and the hazard specification is

$$
\lambda_{i c}(t)=\lambda_{0}(t) e^{\beta_{t} X_{i c t}}
$$

with $\boldsymbol{X}_{\text {ict }}$ defined as above, except with an additional control for an interaction of $P F L$ with a quartic function of leave duration. $\lambda_{0}(t)$, the baseline hazard rate for week (or day) $t$, is estimated non-

\footnotetext{
${ }^{20}$ In our application, once a mother (or father) moves off leave, either by returning to work or exiting the labor force, she exits the sample.
} 
parametrically. ${ }^{21}$ The corresponding survivor rate, $\Phi_{i c}(T)$, is the cumulative product of (one minus) the individual hazard rates, or

$$
\Phi_{i c}(T)=\prod_{t=1}^{T}\left(1-\lambda_{i c}(t)\right)
$$

Descriptive characteristics, weighted so as to be representative, are provided for mothers and fathers in Appendix tables A.1 and A.2, with separate results presented for California and the control states and for periods before after CA-PFL implementation. The combined (California plus control state) sample contains 1,762 births for mothers and 1,728 births for fathers. California parents are less likely to be black and more often Hispanic than parents from other states. As expected, since the NLSY-97 follows a cohort, those giving birth before July 2004 are younger, have less education and work experience, are less likely to be married, and have fewer children than counterparts whose children are born later. However, these parents reside in households with more members.

\section{Leave-Taking}

Figure 1 presents the daily regression-adjusted proportion of mothers in our sample on leave during the 12 weeks before and 39 weeks after giving birth. These are obtained from estimates of equation (2) which, as discussed, distinguish births before and after July of 2004 and in California versus other (control) states, and adjusts for differences in race/ethnicity, age, education, marital status, work experience, family size, and number of children.

The figure provides strong evidence that $C A-P F L$ increased leave-taking. Prior to the program's enactment, new mothers in California took roughly the same amount of leave as their

${ }^{21}$ Specifically, we use the probit functional form (see Maddala, 1983) for $\lambda_{i c}(t)$, including duration dummy variables which allow the baseline hazard to take a value in each period that best fits the data, instead of being forced to follow a trend that is partially determined by other durations. 
control state counterparts in the weeks immediately before birth and slightly more two to eight weeks after it (probably reflecting the availability of temporary disability insurance in California). There was no change, or possibly even a slight decrease, in leave-taking outside of California after July of 2004, whereas its use increased fairly dramatically for California mothers over the same period.

Additional details are provided in the first two columns of Table 1, which shows differencesin-differences estimates (the estimated marginal effects on the $C A \times P O S T$ interaction in equation 1) along with the associated standard errors, for specified time periods after the births. For example, the first table entry indicates that California’s paid leave program raised estimated leave-taking one day after birth by a highly significant 17.5 percentage points (from a baseline of $57.7 \%$ ). The DD estimates indicate that PFL was associated with a 17 to 20 percentage point increase in leave-taking during the first five weeks after birth and 20 to 34 point growth during the next eight weeks. The effect shrinks rapidly thereafter, although generally remaining statistically significant through the child's first four months. These patterns make sense since PFL is expected to have the strongest effect during the period immediately after the expiration of Temporary Disability Insurance benefits, which generally exhaust for mothers six to eight weeks after the birth.

PFL also appears to have increased the leave-taking of fathers, but with three important differences. First, the strongest effects occur almost immediately after the birth, rather than being delayed by several weeks (see Figure 2 and the last two columns of Table 1). This is again consistent with a causal effect of $C A-P F L$, since many women will be on TDI leave after delivery, which fathers are not eligible for. Second, the absolute magnitude of the effect is much smaller - peaking at 8 to 9 percentage points for men versus 30 to 35 points for women. However, since the baseline rates of leave-taking are also dramatically lower for fathers (17.0\% percent just after birth versus 57.7\% 
for mothers) the estimated effects are of approximately equal size in relative terms. ${ }^{22}$ Third, fathers remain on leave relatively briefly, even after the enactment of paid family leave, with less than 6 percent still off the job by the end of the child's third week and below 1 percent after the seventh week. ${ }^{23}$ By contrast, after the enactment of PFL, 53.3\% of California mothers and $28.5 \%$ of those in control states were still not at work seven weeks after delivery.

Further detail on how CA-PFL affected the timing of leave-taking is provided in Table 2 and Figures 3 through 6, which show estimated parental leave hazard and survival rates after controlling for demographic characteristics. Specification 1, in Table 2, constrains the effects to be proportional in each week after birth; in specification 2 and the figures, the effects of $C A-P F L$ on the hazard rates are allowed to vary nonlinearly with leave durations: this is done by interacting a quartic polynomial of time on leave with the indicator for the post-PFL implementation period (with California and Post main effects also controlled for).

$C A-P F L$ reduces the estimated average weekly hazard rate out of leave by a statistically significant 4 to 6 percent for both men and women (see specification 1). However, as shown in specification 2, the predicted effects vary substantially over time. For mothers, the hazard rates fall immediately after the birth but with the largest decrease occurring 6 to 14 weeks subsequent to it and with a negative effect persisting until around the $18^{\text {th }}$ week, after which the pattern reverses and $C A$ PFL is associated with higher hazard rates (Figure 3). This last effect occurs because fewer than five percent of California mothers remained on leave through the $18^{\text {th }}$ week prior to 2004, versus around

${ }^{22}$ Applebaum and Milkman (2011) indicate the proportion of fathers taking paid leave after a child's birth in California increased from 17 percent in 2004 to 26 percent in 2010.

${ }^{23}$ On a related point, we do not show regression-adjusted effects for fathers beyond two weeks, in Table 1, because no California fathers remained on leave after 14 days during the pre-PFL period. 
10 percent after the law's passage (see Figure 4), so that hazard rates became necessarily low in the pre-program period. Almost no mothers remain on leave beyond six months, either before or after the enactment of California paid leave. For fathers, the reduction in leave hazard rates is immediate, peaking one week after the birth and with a higher exit rate predicted during the post-PFL period after the second post-birth week (Figure 5), reflecting the extremely low rates at which fathers took more than two weeks of leave before 2004 (see Figure 6). These results suggest a causal impact of CA-PFL. Specifically, the reduction in expected hazard rates is largest for women during the several weeks after the exhaustion of temporary disability insurance benefits, six to eight weeks after birth, but immediately after it for men, who do not have access to TDI.

Using the predicted survivor rates, displayed in Figures 4 and 6, we estimate that $C A-P F L$ raised average leave-taking from 7.5 to 10.5 weeks for new mothers and from 10.5 to 17.0 days for new fathers. ${ }^{24}$ This implies that the average mother is taking half of the statutory duration of the program as additional leave (3.0 of 6 weeks) and that the average father is taking a bit less than onesixth of the newly available leave (6.5 days out of the 6 weeks). In addition to these net increases, there may be some replacement of time off work that would have otherwise been taken as unpaid or company paid leave. These average effects conceal substantial variation in leave use across parents. For instance we estimate that leave increased by around two (four) weeks for mothers at the $25^{\text {th }}$ $\left(75^{\text {th }}\right)$ percentiles of leave use and by 3 (10) days for corresponding fathers.

\section{Other Labor Market Outcomes}

The increase in leave-taking due to $C A-P F L$ reflects a small reduction in non-employment combined with a larger decrease in work among those who remain employed (but on leave). This is shown in Table 3, which provides separate estimates for nonemployment and work, as well as for

${ }^{24}$ This is calculated as $\Sigma_{t} \Phi(t) \times t$, for $\Phi(t)$ the probability of being on leave $t$ periods after the birth. 
continuation in the job held prior to childbirth. For instance, at the end of the first post-birth week, the 17.8 percentage point rise in predicted leave-taking (shown in Table 1 and previously discussed), consisted of a 3.2 percentage point decline in non-employment and a 13.3 point reduction in work. As mentioned, large predicted effects on maternal leave-taking persist through the fourth month after delivery and, at almost all of these intervals, are accompanied by strong reductions in work and much weaker (and usually statistically insignificant) declines in non-employment. Additional detail on the components of these DD estimates - the regression-adjusted labor market status of California and control state mothers before and after CA-PFL enactment - are provided in Figures 7 and 8.

The intermediate-term labor market effects are equally interesting. $C A-P F L$ is associated with increased leave-taking and reduced rates of work during the first four months or so after birth, as mentioned; however, by month six the leave-taking is complete and the negative predicted effects on work have been eliminated. By nine months after birth, $C A-P F L$ is predicted to increase work probabilities and to reduce non-employment by a statistically significant five to six percentage points, an effect which persists through at least the end of the first year.

Researchers previously examining (mostly unpaid) state and federal leave entitlements (Washbrook, et al., 2011), as well as California’s paid family leave program (Rossin-Slater, et al., 2013) have also found that leave rights initially reduce but subsequently increase rates of work. The reason generally hypothesized for the positive intermediate-term effect is that the availability of leave reduces quits and raises the probability that mothers remain with their pre-birth employer. We explore this possibility in the last two columns of Table 3 and in Figure 9, where the dichotomous outcome indicates whether the mother is working at the last job held prior to giving birth.

Our main specifications provide little evidence that $C A-P F L$ increased job continuity. Specifically, California mothers are predicted to be between a half and one percentage point more 
likely to work at their pre-birth job nine or twelve months after delivery, after enactment of the paid leave program, but the effect does not approach statistical significance. The reason the impact is so small is that the vast majority of the mothers analyzed (over 80 percent for all groups) eventually return to their old jobs. However, this could partially reflect our sample inclusion requirement of having worked at least 32 weeks during the pregnancy. Specifically, the availability of paid leave might induce some mothers to work more during this period and take short paid leaves after it, rather than quitting the job held during pregnancy, thereby increasing job continuity. This possibility is examined below.

\section{Robustness Checks}

We next test whether the preceding results are robust to changes in the choice of control states or sample inclusion criteria. Table 4 summarizes the results. The top panel shows our base model, where the comparison group consists of all states other than California as controls and the sample includes mothers employed at least 32 weeks of the pregnancy period. The second and third panels restrict the comparison group to a reduced set of matched control states. Specifically, control states in the second panel are those with leaving-taking trends from 2000 to July 2004 similar to those in California over the same period. The third panel uses a variant of the methodology developed by Abadie, Diamond, and Hainmueller (2010) to create a synthetic control state for California from other states, also based on pre-July 2004 leave-taking trends. We describe the procedures for choosing these alternative control groups in Appendix B. The fourth and fifth panels return to the original comparison of California versus all other states but reduce the pre-birth work requirement for inclusion in the analysis to 20 weeks (panel 4) and any employment during the nine months before the birth (panel 5). 
Most results are insensitive to these changes. Restricting the control group to either of the alternative control states has little impact. Weakening the pregnancy period work requirement does not materially or consistently affect the results for leave-taking but changes the estimated $C A-P F L$ effect on nonemployment and work in two ways. First, higher levels of employment explain a greater portion of the increase in leave-taking, with a consequent decrease in the contribution of reductions in work. For instance, $C A-P F L$ is predicted to reduce the nonemployment of mothers by 5.4 percentage points, 4 weeks after the birth, when the sample includes those working at least 20 weeks during pregnancy, versus a 0.8 point decrease when restricting the analysis to those who worked at least 32 weeks during that period; the accompanying reduction in work probabilities is 15.1 rather than 18.2 percentage points. Second, the medium-term increases in employment, work and return to the pre-birth job are considerably larger when using less restrictive sampling criteria. Thus, PFL is predicted to raise the probability of having returned to work within one year by 8.6 (7.7) percentage points and to have done so with the pre-birth employer by 3.5 (6.6) points among mothers with any (at least 20) weeks of work during pregnancy, compared to 5.4 and -0.8 percentage point changes for the main sample.

This suggests that $C A-P F L$ increases the job continuity of new mothers in ways that our main estimates do not capture. Specifically, by restricting the sample to persons with substantial pre-birth employment prior, we may be ignoring reductions in quit rates that paid leave facilitates. Without paid time off the job, some mothers planning to stop working once their children are born may leave their positions before delivery and therefore be excluded from our analysis. However, when paid leave is available, some of them choose not to quit their jobs but rather to take some time off work and then return to their original employer. This could also help to explain the PFL-related reduction in nonemployment observed immediately after childbirth. While an argument could be made for 
using a less stringent pregnancy work requirement as our main specification, the tradeoff is that doing so is likely to include more parents who would not continue to be employed to the point where leave rights become a relevant consideration.

\section{Wages, Earnings, and Work}

Last, we examine how California’s paid family-leave program has influenced longer-term labor market outcomes of mothers including: the probability of having returned to work within one year of the birth, log hourly wages at this time, and the average number of weeks and hours worked during the second year of the child's life. The analysis samples are smaller than those above for two reasons. First, labor market status will be unavailable for mothers giving birth near the end of the analysis period. Second, wage data are missing for women who are not employed at the end of the relevant time period and are not provided for some working mothers. ${ }^{25}$

Our main results, summarized in the top panel of Table 5, confirm that CA-PFL increases rates of maternal work one year after the child's birth. Specifically, the DD estimate suggests that the paid leave program raised the work probabilities of mothers by 4.8 percentage points one year after birth, compared to a pre-PFL baseline of 91 percent. $^{26}$ This is smaller than the 5.4 point increase obtained in Table 4 (with a slightly larger sample and longer time period) but the difference does not approach statistical significance. Rights to paid leave are also predicted to elevate weeks worked and average weekly work hours during the second year of the child's life - by 6.9 weeks and 2.9 hours which represent 19 and 11 percent growth compared over the pre-program baselines of 36.8 weeks and 25.9 hours per week. At least some of this increase is expected, since rights to paid leave significantly increased the probability of having returned to work by the end of the child's first year.

\footnotetext{
${ }^{25}$ We found no evidence of differential patterns in missing data for California versus control state mothers. ${ }^{26}$ These are marginal effects estimated from probit models.
} 
Finally, the point estimates suggest that hourly wages increase by around seven percent, one year after the birth, but the confidence intervals are wide and include zero or negative effects.

The bottom panel of Table 5 shows that we obtain fairly similar results when broadening the sample to include mothers with any pre-birth employment. ${ }^{27}$ The one change is that there is a considerably larger predicted increase in the probability of returning to work by 52 weeks after the birth -7.1 versus 4.8 percentage points - which is consistent with the results previously described in Table 4 and again suggests a positive $C A-P F L$ effect on job continuity. ${ }^{28}$

\section{Discussion}

Our analysis indicates that California’s paid family leave program raised the leave-taking of new mothers and fathers. These increases are sizable and last for four months after the birth for mothers and two weeks subsequent to it for fathers. For mothers, the effects are most pronounced during the sixth through thirteenth weeks after delivery - an estimated 21 to 33 percentage point increase - which corresponds to the period after the exhaustion of temporary disability benefits. Fathers are not eligible for pregnancy-related TDI and the PFL effects for them begin immediately after birth and are largest during the following week. Although the overall increase in leave-taking for father is much smaller than for mothers - between 4 and 9 percentage points during the first two weeks - the baseline levels are also dramatically lower, so that these effects are large in relative

${ }^{27}$ As expected, the baseline rates of post-birth work are lower for this group, since it includes mothers with weaker attachments to the labor force.

${ }^{28}$ The effect on log wages at the end of year 1 and weeks or hours worked during year 2 are also similar for the other three samples shown in Table 4 (mothers from both sets of alternative control states and those in California and control states working 20 or more weeks during pregnancy), and the patterns of return to work by the end of the first year also correspond with those found there. 
terms. We estimate $C A-P F L$ increased the average leave-taking of mothers by around three weeks and that of fathers by approximately one week.

We also examined other labor market consequences of the paid leave program for mothers. The increased leave-taking immediately after birth results from a combination of reductions in work among the employed and higher rates of employment, with the former being more important in most specifications. There is consistent evidence that CA-PFL increased the likelihood that mothers have returned to work by a year after birth and raised maternal hours and weeks of work by 11 to 19 percent during the second year of the child's life. Paid leave is also predicted to raise hourly wages at the end of the first year by 7 percent, but this estimate is imprecise and statistically insignificant. Finally, there is some indication that the medium-term increases in the probability of working may reflect increases in job continuity, resulting because paid leave reduces the probability that some expectant mothers quit their jobs prior to giving birth.

It is useful to compare these results to the recent study of California paid leave conducted by Rossin-Slater et al. (2013). In their main specifications, the program is predicted to raise the average leave-taking of eligible mothers by 3.1 to 3.3 weeks, with modestly smaller estimates obtained in some alternative specifications. The similarity of these results to ours is noteworthy given that they use a different data set - the 1999 to 2010 years of the March Current Population Survey - that contains a larger sample but less precise information on leave-taking. ${ }^{29}$ They also find positive medium-term effects of $C A-P F L$ on maternal employment that appear to be of comparable size or somewhat smaller than those that we observe. ${ }^{30}$ For example, rights to paid leave are anticipated to raise the weekly work hours of mothers with one-year-old children by 2 to 3 hours per week, versus

\footnotetext{
${ }^{29}$ Information on leave-taking is only available for the week prior to the survey.

30 They examine hours worked in the last week and last year for mothers of one to three year olds.
} 
a 2.9 hour per week increase obtained here. They also (imprecisely) estimate annual earnings increases of around 13 percent for these mothers, largely reflecting growth in predicted work hours rather than hourly wages. Our point estimate is larger - an 11 percent increase in work hours and a 6 to 7 percent rise in hourly wages implies around an 18 percent rise in annual earnings - but again with standard errors that are easily big enough to encompass the Rossin-Slater et al. estimate. ${ }^{31}$

Our analysis extends beyond that of Rossin-Slater, et al. (2013) in at least three important ways. First, the detailed NLSY-97 work history data permit us to identify increases in paternal leavetaking that are modest in absolute size (around a week) but large in relative terms, 40 to 50 percent increase from a low baseline. Interestingly, such results are consistent with Han, et al.’s (2009) evidence that (largely unpaid) federal and state leave entitlements are associated with 50 percent or larger increases in leave-taking by fathers during the birth month, from extremely low baseline rates.

Second, we are able to more precisely measure the timing of leave-taking. As mentioned, the patterns of leave use - immediately after births for fathers and reaching a maximum shortly after temporary disability benefits are likely to be exhausted for most mothers - suggest that we are observing a causal effect of CA-PFL. In addition, using predicted changes in survivor probabilities at different durations, we can estimate the distribution of the rise in leave-taking. Doing so, we find that the $25^{\text {th }}$ percentile of the leave-taking distribution increases from just over 5 weeks to 7 weeks, the $50^{\text {th }}$ percentile from 8 to 10 weeks, and the $75^{\text {th }}$ percentile from about 10 to 14 weeks. Similarly, for fathers the $25^{\text {th }}, 50^{\text {th }}$, and $75^{\text {th }}$ percentiles of the leave-taking distribution increase from 3 to 6,6 to 13 , and 11 to 24 days respectively.

${ }^{31}$ The confidence intervals on Rossin-Slater et al. (2013) predictions are also wide and they estimate a larger (21 percent) annual earnings increase for mothers with three year old children. 
Third, our results suggest that paid leave increases the job continuity of new mothers but that the mechanism by which this occurs is to encourage a subset of women to remain working through the end of their pregnancy so that they qualify for a period of paid leave and then can return to their pre-birth employer.

Some analysts advocate expanding California's paid family leave program by further publicizing its existence, raising the wage replacement rate, extending coverage to public sector employees, and providing job protection during the leave. ${ }^{32}$ Our results indicate that the program, as currently structured, has appreciable effects on leave-taking and work, so that these extensions are likely to have noticeable effects as well. The cost of PFL mandates depends on the frequency and duration with which parents take paid leave, the amount of wages replaced, and administrative costs (including employer and employee accommodations for absent employees). The findings of this analysis can be used to address the first two components of this cost. Also, the models examining whether mothers return to the pre-birth employers raise the possibility of cost offsets, if $C A-P F L$ helps to preserve employer-employee matches and firm-specific human capital. This information is also relevant, for California policymakers setting the employee-paid payroll tax rate used to finance the program. Finally, advocates of national paid family leave programs (e.g. O’Leary et al., 2012;

${ }^{32}$ In 2009-2010, a majority of California workers in did not know about the PFL program and a third of those who knew of it did not apply for the benefits because the wage replacement was too low; others did not take paid leave because they thought they were ineligible or feared that doing so would limit their future advancement or result in employment termination (Applebaum and Milkman, 2011). 
Zigler et al., 2012) draw heavily on the California experience and propose to incorporate many of its key features in their proposals, making these findings particularly salient. 


\section{References}

Abadie, Alberto, Alexis Diamond, and Jens Hainmueller. (2010). “Synthetic Control Methods for Comparative Case Studies of Aggregate Interventions: Estimating the Effect of California's Tobacco Control Program.” Journal of the American Statistical Association, 105 (490): 493-505.

Albrecht, James W., Per-Anders Edin, Marianne Sundstrom, and Susan B. Vroman. (1998). "Career Interruptions and Subsequent Earnings: A Reexamination Using Swedish Data." Journal of Human Resources, 34(2), 294-311.

Applebaum, Eileen, and Ruth Milkman. (2011). "Leaves that Pay: Employer and Worker Experiences with Paid Family Leave in California.” Policy Report. Washington, D.C.: Center for Economic and Policy Research.

Baker, Michael and Kevin Milligan (2010). “Evidence from Maternity Leave Expansions of the Impact of Maternal Care on Early Child Development.” Journal of Human Resources, 45(1): 132 .

Baker, Michael, and Kevin Milligan. (2008). "How Does Job-Protected Maternity Leave Affect Mothers’ Employment." Journal of Labor Economics, 26(4), 655-691.

Baum, Charles L. (2003a). "The Effects of State Maternity Leave Legislation and the 1993 Family and Medical Leave Act on Employment and Wages.” Labour Economics, 10(5): 573-596.

Baum, Charles L. (2003b). “The Effects of Maternity Leave Legislation on Mothers’ Labor Supply Patterns after Childbirth.” Southern Economic Journal, 69(4): 772-799.

Berger, Lawrence M., and Jane Waldfogel. (2004). "Maternity Leave and the Employment of New Mothers in the United States." Journal of Population Economics, 17(2), 331-349.

Berger, Berger, Jennifer Hill and Jane Waldfogel. (2005). "Maternity Leave, Early Maternal Employment and Child Health and Development in the US.” Economic Journal 115(501): F29-F47

Bertrand, Marianne, Esther Duflo, and Sendhil Mullainathan. (2004). "How Much Should We Trust Difference-in-Differences Estimates?” Quarterly Journal of Economics, 119(1): 249-275.

Chatterji, Pinka and Sara Markowitz. (2005). "Does the Length of Maternity Leave Affect Maternal Health,” Southern Economic Journal 72(1): 16-41.

Department of Labor and Workforce Development, State of New Jersey. (2014). Benefit Calculation and Duration of Benefits, http://lwd.dol.state.nj.us/labor/fli/worker/state/FL_SP_calculating_benefits.html, accessed August 7, 2014.

Employment Development Department, State of California. (2014). Disability Insurance (DI) and Paid Family Leave (PFL) Weekly Benefit Amounts, http://www.edd.ca.gov/pdf_pub_ctr/de2588.pdf, accessed August 7, 2014. 
Employment Security Department, Washington State. (2013). Family Leave Insurance, http://www.esd.wa.gov/newsandinformation/legresources/family-leave-insurance.php, accessed February 25, 2013.

Fass, Sarah. (2009). "Paid Leave in the States: A Critical Support for Low-Wage Workers and Their Families.” Research Report. New York, NY: Columbia University, National Center for Children in Poverty.

Gupta, Nabanita Datta, Nina Smith, and Mette Verner. (2008). “The Impact of Nordic Countries' Family Friendly Policies on Employment, Wages, and Children.” Review of Economics of the Household, 6(1): 65-89.

Han, Wen-Jui, Christopher J. Ruhm, and Jane Waldfogel. (2009). "Parental Leave Policies and Parental Employment and Leave-Taking.” Journal of Policy Analysis and Management, 28(1): 29-54.

Han, Wen-Jui, and Jane Waldfogel. (2003). "Parental Leave: The Impact of Recent Legislation on Parents’ Leave Taking.” Demography, 40(1): 191-200.

Hanratty, Maria, and Eileen Trzcinski. (2009). "Who Benefits from Paid Leave? Impact of Expansions in Canadian Paid Family Leave on Maternal Employment and Transfer Income.” Journal of Population Economics, 22(3): 693-711.

Haymann, Jody, Allison Earle, and Jeffrey Hayes. (2007). “The Work, Family, and Equity Index.” Research Report. Montreal, Quebec: McGill University, Project on Global Working Families and the Institute for Health and Social Policy.

Klerman, Jacob, and Arleen Leibowitz. (1999). “Job Continuity Among New Mothers.” Demography, 36(2): 145-155.

Klerman, Jacob, and Arleen Leibowitz. (1997). “Labor Supply Effects of State Maternity Leave Legislation” in Francine Blau and Ronald Ehrenberg (eds.) Gender and Family Issues in the Workplace. New York: Russell Sage: 65-85.

Klerman, Jacob A., Kelly Daley, and Alyssa Pozniak. (2012). Family and Medical Leave in 2012: Technical Report, prepared for the U.S. Department of Labor (Contract \#GS10FOO86K). Cambridge, MA: Abt Associates, http://www.dol.gov/asp/evaluation/fmla/FMLATechnicalReport.pdf, accessed February 26, 2013.

Lalive, Rafael, and Josef Zweimuller. (2009). "How Does Parental Leave Affect Fertility and Return to Work? Evidence from Two Natural Experiments.” Quarterly Journal of Economics, 124(3): 1363-1402.

Maddala, G.S. (1983). Limited-Dependent and Qualitative Variables in Econometrics. Cambridge, England: Cambridge University Press.

Meyer, Bruce. (1995). “Semiparametric Estimation of Hazard Models.” Unpublished Manuscript. Chicago, IL: Northwestern University. 
Meyer, Bruce. (1990). "Unemployment Insurance and Unemployment Spells.” Econometrica, 58(4), 757-782.

O’Leary, Ann, Matt Chayt and Eve Weissman. (2012) Social Security Cares: Why America is Ready for Paid Family and Medical Leave. Washington D.C.: Center for American Progress.

Ondrich, Jan, C. Katherine Spiess, Qing Yang, and Gert G. Wagner. (1999). "Full Time or Part Time? German Parental Leave Policy and the Return to Work after Childbirth in Germany." Research in Labor Economics, 18(1): 41-74.

Prentice, R. and L. Gloeckler (1978). "Regression Analysis of Grouped Survival Data with Application to Breast Cancer Data.” Biometrics, 34(1), 57-67.

Progressive States Network. (2010). "Maternity/Paternity Leave (Paid Family Leave).” Research Report. New York, NY: http://www.progressivestates.org/content/369/maternity-andpaternity-leave\#paidleave.

Pronzato, Chiara Daniela. (2009). "Return to Work after Childbirth: Does Parental Leave Matter in Europe?” Review of the Economics of the Household, 7(4): 341-360.

Rossin, Maya. (2011). "The Effects of Maternity Leave on Children’s Birth and Infant Health Outcomes in the United States.” Journal of Health Economics, 30(2), 221-239.

Rossin-Slater, Maya, Christopher J. Ruhm, and Jane Waldfogel. (2013). “The Effects of California’s Paid Family Leave Program on Mothers’ Leave-Taking and Subsequent Labor Market Outcomes.” Journal of Policy Analysis and Management, 32(2), 224-245.

Ruhm, Christopher J. (2011). "Policies to Assist Parents with Young Children.” The Future of Children, 21(2): 37-68.

Ruhm, Christopher J. (2000). "Parental Leave and Child Health.” Journal of Health Economics, 19(6): 931-960.

Ruhm, Christopher J. (1998). "The Consequences of Parental Leave Mandates: Lessons from Europe.” Quarterly Journal of Economics, 113(1): 285-318.

Ruhm, Christopher J., and Jackqueline L. Teague. (1997). "Parental Leave Policies in Europe and North America," in Francine Blau and Ronald Ehrenberg (eds.) Gender and Family Issues in the Workplace. New York: Russell Sage, 133-157.

Schonberg, Uta, and Johannes Ludsteck. (2007). "Maternity Leave Legislation, Female Labor Supply, and the Family Wage Gap." Discussion Paper. Bonn, Germany: IZA Institute for the Study of Labor, Discussion Paper No. 2699.

Tanaka, Sakiko. (2005). "Parental Leave and Child Health in OECD Across Countries.” Economic Journal, 15(501): F7-F28. 
Waldfogel, Jane. (1999). “The Impact of the Family and Medical Leave Act.” Journal of Policy Analysis and Management, 18(2): 281-301.

Washbrook, Elizabeth, Christopher J. Ruhm, Jane Waldfogel and Wen-Jui Han. (2011). "Public Policies, Women's Employment After Childbearing, and Child Well-Being." The B.E. Journal of Economic Analysis and Policy, 11(1 - Topics), Article 43.

Zigler, Edward, Susan Muenchow and Christopher J. Ruhm. (2012). Time Out With Baby: The Case for Paid Parental Leave. Washington, D.C.: Zero to Three. 
Table 1: Regression-Adjusted Estimated Effects of CA-PFL on Leave-Taking

\begin{tabular}{|c|c|c|c|c|}
\hline Time Period & \multicolumn{2}{|c|}{ Mothers } & \multicolumn{2}{|c|}{ Fathers } \\
\hline Day 1 & $0.175 * * *$ & $(0.034)$ & $0.042 *$ & $(0.026)$ \\
\hline Day 2 & $0.176 * * *$ & $(0.033)$ & $0.073 * *$ & $(0.030)$ \\
\hline Day 4 & $0.174 * * *$ & $(0.033)$ & $0.068 * *$ & $(0.029)$ \\
\hline Day 6 & $0.172 * * *$ & $(0.035)$ & $0.090 * * *$ & $(0.030)$ \\
\hline Day 7 & $0.178 * * *$ & $(0.033)$ & $0.086 * * *$ & $(0.028)$ \\
\hline Day 8 & $0.181^{* * *}$ & $(0.033)$ & $0.053 * *$ & $(0.025)$ \\
\hline Day 10 & $0.191^{* * *}$ & $(0.033)$ & $0.067 * *$ & $(0.028)$ \\
\hline Day 12 & $0.192 * * *$ & $(0.032)$ & $0.035^{*}$ & $(0.020)$ \\
\hline Week 2 & $0.182^{* * *}$ & $(0.033)$ & $0.056 * *$ & $(0.024)$ \\
\hline Week 3 & $0.196 * * *$ & $(0.035)$ & - & - \\
\hline Week 4 & $0.178 * * *$ & (0.038) & - & - \\
\hline Week 5 & $0.181^{* * *}$ & $(0.038)$ & - & - \\
\hline Week 6 & $0.233 * * *$ & $(0.038)$ & - & - \\
\hline Week 7 & $0.243 * * *$ & $(0.045)$ & - & - \\
\hline Week 8 & $0.332 * * *$ & $(0.051)$ & - & - \\
\hline Week 10 & $0.329 * * *$ & $(0.044)$ & - & - \\
\hline Week 13 & $0.213 * * *$ & $(0.039)$ & - & - \\
\hline Week 16 & $0.123^{* * *}$ & $(0.041)$ & - & - \\
\hline Week 18 & $0.056 * *$ & $(0.027)$ & - & - \\
\hline Week 20 & $0.042 *$ & $(0.023)$ & - & - \\
\hline Week 26 & 0.001 & $(0.005)$ & - & - \\
\hline Week 34 & -0.001 & $(0.002)$ & - & - \\
\hline Week 39 & -0.002 & $(0.002)$ & - & - \\
\hline
\end{tabular}

Note: ${ }^{* * *} \mathrm{p}<0.01, * * \mathrm{p}<0.05, * \mathrm{p}<0.1$. Table shows difference-in-difference estimates (coefficients on CA×POST interactions). The models also control for California and postJuly 2004 main effects, as well as race/ethnicity, age, education, marital status, work experience, family size, and the number of biological children. Robust standard errors, clustered at the state level, are in parentheses. There are 1,762 birth observations for mothers and 1,728 birth observations for fathers who were employed in at least 32 pregnancy weeks from California and all other states. No California fathers are on leave beyond 14 days in the pre-PFL period, so estimates are not provided at those durations. 
Table 2: Estimated Effects of CA-PFL on Hazard Rates Out of Leave

\begin{tabular}{|c|c|c|c|c|}
\hline Time Period & \multicolumn{2}{|c|}{ Mothers } & \multicolumn{2}{|c|}{ Fathers } \\
\hline \multicolumn{5}{|l|}{ Specification 1} \\
\hline PFL & $-0.054 * * *$ & $(0.010)$ & $-0.044 * * *$ & $(0.012)$ \\
\hline \multicolumn{5}{|l|}{ Specification 2} \\
\hline PFL*Weeks/100 & $-0.081 * * *$ & $(0.018)$ & $-0.213^{* * *}$ & $(0.039)$ \\
\hline PFL *Weeks²/1000 & 0.255 & $(0.261)$ & $2.286 * * *$ & $(0.457)$ \\
\hline PFL*Weeks ${ }^{3} / 10000$ & 0.146 & $(0.111)$ & $-0.723^{* * *}$ & $(0.167)$ \\
\hline PFL*Weeks ${ }^{4} / 100000$ & $-0.038 * * *$ & $(0.056)$ & $0.073 * * *$ & (0.019) \\
\hline
\end{tabular}

Note: $* * * \mathrm{p}<0.01, * * \mathrm{p}<0.05, * \mathrm{p}<0.1$. Table shows difference-in-difference estimates (coefficients on $C A \times P O S T$ interactions), with the same controls as in Table 1 . Robust standard errors, clustered at the state level, are in parentheses. Discrete time hazard models are estimated. There are 9,086 birth-week observations from 1,037 births for mothers and 3,282 birth-day observations from 278 births for fathers in the paid leave hazard model from California and all other states. 
Table 3: Regression-Adjusted Estimated Effects of CA-PFL on the Labor Market Status of Mothers

\begin{tabular}{|c|c|c|c|c|c|c|}
\hline \multirow{2}{*}{$\frac{\text { Time Period }}{\text { Week } 1}$} & \multicolumn{2}{|c|}{ Not Employed } & \multicolumn{2}{|c|}{$\underline{\text { Returned to Work By }}$} & \multicolumn{2}{|c|}{ Returned to Old Job By } \\
\hline & -0.032 & $(0.025)$ & $-0.133 * * *$ & $(0.020)$ & $-0.133 * * *$ & $(0.020)$ \\
\hline Week 2 & -0.032 & $(0.023)$ & $-0.138 * * *$ & $(0.020)$ & $-0.138 * * *$ & $(0.020)$ \\
\hline Week 3 & -0.007 & $(0.026)$ & $-0.177 * * *$ & $(0.019)$ & $-0.175^{* * *}$ & $(0.019)$ \\
\hline Week 4 & 0.008 & $(0.027)$ & $-0.182 * * *$ & $(0.022)$ & $-0.181 * * *$ & $(0.022)$ \\
\hline Week 5 & 0.006 & $(0.025)$ & $-0.185 * * *$ & $(0.023)$ & $-0.184 * * *$ & $(0.022)$ \\
\hline Week 6 & -0.022 & $(0.023)$ & $-0.207 * * *$ & $(0.029)$ & $-0.215^{* * *}$ & $(0.028)$ \\
\hline Week 7 & -0.013 & $(0.024)$ & $-0.231 * * *$ & $(0.032)$ & $-0.243 * * *$ & $(0.031)$ \\
\hline Week 8 & $-0.061 * * *$ & $(0.019)$ & $-0.233 * * *$ & $(0.042)$ & $-0.247 * * *$ & $(0.040)$ \\
\hline Week 10 & 0.022 & $(0.028)$ & $-0.316 * * *$ & $(0.040)$ & $-0.339 * * *$ & $(0.036)$ \\
\hline Week 13 & -0.002 & $(0.022)$ & $-0.187 * * *$ & $(0.031)$ & $-0.226 * * *$ & $(0.030)$ \\
\hline Week 16 & -0.013 & $(0.020)$ & $-0.079 * * *$ & $(0.026)$ & $-0.126 * * *$ & $(0.030)$ \\
\hline Week 18 & -0.013 & $(0.019)$ & $-0.058 * *$ & $(0.026)$ & $-0.103 * * *$ & $(0.030)$ \\
\hline Week 20 & -0.025 & $(0.019)$ & -0.025 & $(0.024)$ & $-0.076 * * *$ & $(0.029)$ \\
\hline Week 26 & -0.012 & $(0.015)$ & 0.009 & $(0.015)$ & -0.013 & $(0.023)$ \\
\hline Week 34 & $-0.023^{* *}$ & $(0.011)$ & 0.024 & $(0.011)$ & -0.003 & $(0.020)$ \\
\hline Week 39 & $-0.050 * * *$ & $(0.008)$ & $0.054 * * *$ & $(0.008)$ & 0.006 & (0.019) \\
\hline Week 52 & $-0.052 * * *$ & $(0.008)$ & $0.054^{* * *}$ & $(0.007)$ & 0.008 & (0.018) \\
\hline
\end{tabular}

Note: $* * * \mathrm{p}<0.01,{ }^{* *} \mathrm{p}<0.05,{ }^{*} \mathrm{p}<0.1$. Table shows difference-in-difference estimates (coefficients on CA $\times P O S T$ interactions), with

the same controls as in Table 1. Robust standard errors, clustered at the state level, are in parentheses. There are 1,762 birth

observations for mothers who were employed in at least 32 pregnancy weeks from California and all other states. 
Table 4: Regression-Adjusted Estimated Effects of CA-PFL on the Labor Market Status of Mothers, Alternative Samples

\begin{tabular}{|c|c|c|c|c|c|c|c|c|}
\hline Time Period & \multicolumn{2}{|c|}{ On Leave } & \multicolumn{2}{|c|}{ Not Employed } & \multicolumn{2}{|c|}{ Returned to Work By } & \multicolumn{2}{|c|}{ Returned to Old Job By } \\
\hline & \multicolumn{8}{|c|}{ Mothers Employed at least 32 Pregnancy Weeks from All States $(\mathrm{N}=1,762)$} \\
\hline Week 1 & $0.178 * * *$ & $(0.033)$ & -0.032 & $(0.023)$ & $-0.138 * * *$ & $(0.020)$ & $-0.138 * * *$ & $(0.020)$ \\
\hline Week 4 & $0.178 * * *$ & $(0.038)$ & 0.008 & $(0.027)$ & $-0.182 * * *$ & $(0.022)$ & $-0.181 * * *$ & $(0.022)$ \\
\hline Week 13 & $0.213^{* * *}$ & $(0.039)$ & -0.002 & $(0.022)$ & $-0.187 * * *$ & $(0.031)$ & $-0.226 * * *$ & $(0.030)$ \\
\hline Week 26 & 0.001 & $(0.005)$ & -0.012 & $(0.015)$ & -0.009 & $(0.015)$ & -0.013 & $(0.023)$ \\
\hline \multirow[t]{2}{*}{ Week 52} & - & - & $-0.052 * * *$ & $(0.008)$ & $0.054 * * *$ & $(0.007)$ & -0.008 & $(0.018)$ \\
\hline & \multicolumn{8}{|c|}{$\begin{array}{l}\text { Mothers Employed at least } 32 \text { Pregnancy Weeks from California and Alternative Controls Based on Pre-Treatment } \\
\text { Trends }(\mathrm{N}=1,188)\end{array}$} \\
\hline Week 1 & $0.166 * * *$ & $(0.048)$ & -0.039 & $(0.031)$ & $-0.126 * * *$ & $(0.028)$ & $-0.126^{* * *}$ & $(0.028)$ \\
\hline Week 4 & $0.135 * * *$ & $(0.053)$ & -0.013 & $(0.037)$ & $-0.157 * * *$ & $(0.027)$ & $-0.156 * * *$ & $(0.027)$ \\
\hline Week 13 & $0.235 * * *$ & $(0.053)$ & 0.005 & $(0.029)$ & $-0.203 * * *$ & $(0.036)$ & $-0.229 * * *$ & $(0.036)$ \\
\hline Week 26 & 0.004 & $(0.008)$ & -0.014 & $(0.021)$ & 0.009 & $(0.022)$ & -0.010 & $(0.032)$ \\
\hline \multirow[t]{2}{*}{ Week 52} & - & - & $-0.058 * * *$ & $(0.011)$ & $0.062 * * *$ & $(0.010)$ & 0.011 & $(0.022)$ \\
\hline & \multicolumn{8}{|c|}{ Mothers Employed at least 32 Pregnancy Weeks from California and Abadie Control States (N=508) } \\
\hline Week 1 & $0.296 * *$ & $(0.150)$ & -0.058 & $(0.072)$ & $-0.242 * *$ & $(0.100)$ & $-0.242 * *$ & $(0.100)$ \\
\hline Week 4 & $0.285^{*}$ & $(0.156)$ & -0.082 & $(0.103)$ & $-0.212 * *$ & $(0.088)$ & $-0.220 * *$ & $(0.080)$ \\
\hline Week 13 & $0.225^{* * *}$ & $(0.052)$ & -0.066 & $(0.057)$ & $-0.163^{* *}$ & $(0.082)$ & -0.142 & $(0.090)$ \\
\hline Week 26 & - & - & -0.020 & $(0.051)$ & 0.009 & $(0.065)$ & 0.067 & $(0.088)$ \\
\hline Week 52 & - & - & $-0.064 * *$ & $(0.029)$ & $0.064 *$ & $(0.035)$ & 0.089 & $(0.078)$ \\
\hline \multicolumn{9}{|c|}{ Mothers Employed at least 20 Pregnancy Weeks from California and All States $(\mathrm{N}=2,187)$} \\
\hline Week 1 & $0.198 * * *$ & $(0.031)$ & $-0.096 * * *$ & $(0.024)$ & $-0.082 * * *$ & $(0.019)$ & $-0.083 * * *$ & $(0.018)$ \\
\hline Week 4 & $0.229 * * *$ & $(0.032)$ & $-0.054 * *$ & $(0.027)$ & $-0.151 * * *$ & $(0.019)$ & $-0.138 * * *$ & $(0.019)$ \\
\hline Week 13 & $0.213 * * *$ & $(0.044)$ & $-0.040 *$ & $(0.023)$ & $-0.122 * * *$ & $(0.030)$ & $-0.106^{* * *}$ & $(0.026)$ \\
\hline Week 26 & 0.002 & $(0.005)$ & $-0.053 * * *$ & $(0.015)$ & $0.051 * * *$ & $(0.016)$ & $0.050 * *$ & $(0.022)$ \\
\hline Week 52 & - & - & $-0.075 * * *$ & $(0.009)$ & $0.077 * * *$ & $(0.009)$ & $0.066 * * *$ & $(0.018)$ \\
\hline
\end{tabular}

Mothers Employed at All during the Pregnancy from California and All States $(\mathrm{N}=2,865)$ 


\begin{tabular}{|c|c|c|c|c|c|c|c|c|}
\hline Week 1 & $0.150 * * *$ & $(0.027)$ & $-0.046^{*}$ & $(0.025)$ & $-0.087 * * *$ & $(0.016)$ & $-0.088 * * *$ & $(0.015)$ \\
\hline Week 4 & $0.172 * *$ & $(0.027)$ & -0.020 & $(0.026)$ & $-0.134 * * *$ & $(0.015)$ & $-0.129 * * *$ & $(0.016)$ \\
\hline Week 13 & $0.162 * * *$ & (0.035) & -0.030 & $(0.021)$ & $-0.107 * * *$ & $(0.023)$ & $-0.113^{* * *}$ & $(0.020)$ \\
\hline Week 26 & 0.002 & $(0.004)$ & $-0.067 * * *$ & $(0.016)$ & $0.064 * * *$ & $(0.016)$ & 0.018 & $(0.020)$ \\
\hline Week 52 & - & - & $-0.085 * * *$ & $(0.011)$ & $0.086 * * *$ & $(0.011)$ & $0.035 * *$ & $(0.018)$ \\
\hline
\end{tabular}

the same controls as in Table 1. Robust standard errors, clustered at the state level, are in parentheses. 
Table 5: Regression-Adjusted Estimated Effects of CA-PFL on the Probability of Working, Weeks and Hours of Work and Wages for Mothers

\begin{tabular}{|c|c|c|c|c|}
\hline & \multirow{2}{*}{$\begin{array}{c}\text { Returned to } \\
\text { Work Within } \\
\text { One Year Of } \\
\text { Birth }\end{array}$} & \multicolumn{2}{|c|}{ Work in $2^{\text {nd }}$ Year After Birth } & \multirow{2}{*}{$\begin{array}{l}\text { Log Hourly Wages, } \\
\text { One Year After Birth }\end{array}$} \\
\hline & & $\begin{array}{c}\text { Annual Weeks } \\
\text { Worked }\end{array}$ & $\begin{array}{c}\text { Weekly Hours } \\
\text { Worked }\end{array}$ & \\
\hline \multicolumn{5}{|c|}{ Mothers Employed at least 32 Pregnancy Weeks } \\
\hline $\begin{array}{l}\text { DD Estimate } \\
\text { Standard Error } \\
\text { Pre-PFL Baseline }\end{array}$ & $\begin{array}{c}0.048 * * * \\
(0.007) \\
{[0.910]}\end{array}$ & $\begin{array}{c}6.893 * * * \\
(1.153) \\
{[36.785]}\end{array}$ & $\begin{array}{l}2.891 * * \\
(1.093) \\
{[25.869]}\end{array}$ & $\begin{array}{c}0.066 \\
(0.048) \\
{[14.15]}\end{array}$ \\
\hline \multicolumn{5}{|c|}{ Mothers Employed at all during Pregnancy } \\
\hline $\begin{array}{l}\text { DD Estimate } \\
\text { Standard Error } \\
\text { Pre-PFL Baseline }\end{array}$ & $\begin{array}{c}0.071 * * * \\
(0.012) \\
{[0.813]}\end{array}$ & $\begin{array}{c}5.723 * * * \\
(1.049) \\
{[33.067]}\end{array}$ & $\begin{array}{c}2.443^{* *} \\
(0.877) \\
{[22.866]}\end{array}$ & $\begin{array}{c}0.049 \\
(0.035) \\
{[12.61]}\end{array}$ \\
\hline
\end{tabular}

Note: ${ }^{* * *} \mathrm{p}<0.01,{ }^{* *} \mathrm{p}<0.05,{ }^{*} \mathrm{p}<0.1$. Table shows difference-in-difference estimates

(coefficients on $C A \times P O S T$ interactions), with the same controls as in Table 1 . Robust standard errors, clustered at the state level, are in parentheses. Pre-PFL sample means in the dependent variables for California mothers are shown in brackets (with levels rather the log of wages displayed in the last column). The probability of working at any job one year after birth is estimated using mothers providing employment information approximately one year (between 47 and 57 weeks) after the birth. Annual weeks and average weekly hours in the second year after birth are measured during the $53^{\text {rd }}$ through $104^{\text {th }}$ weeks after the birth and are not conditional upon employment (i.e. include weeks with zero work hours). Hourly wages, measured in natural logs and 2012-year dollars, refer to those in the first job held during the $47^{\text {th }}$ to $57^{\text {th }}$ weeks subsequent to the birth. Sample sizes are 1,667, 1,420, 1,420 and 1,255 in the top panel for work probabilities, annual weeks worked, weekly hours worked and log hourly wages in the top panel and 2,721, 2,398, 2,398 and 1,827 in the lower panel. 


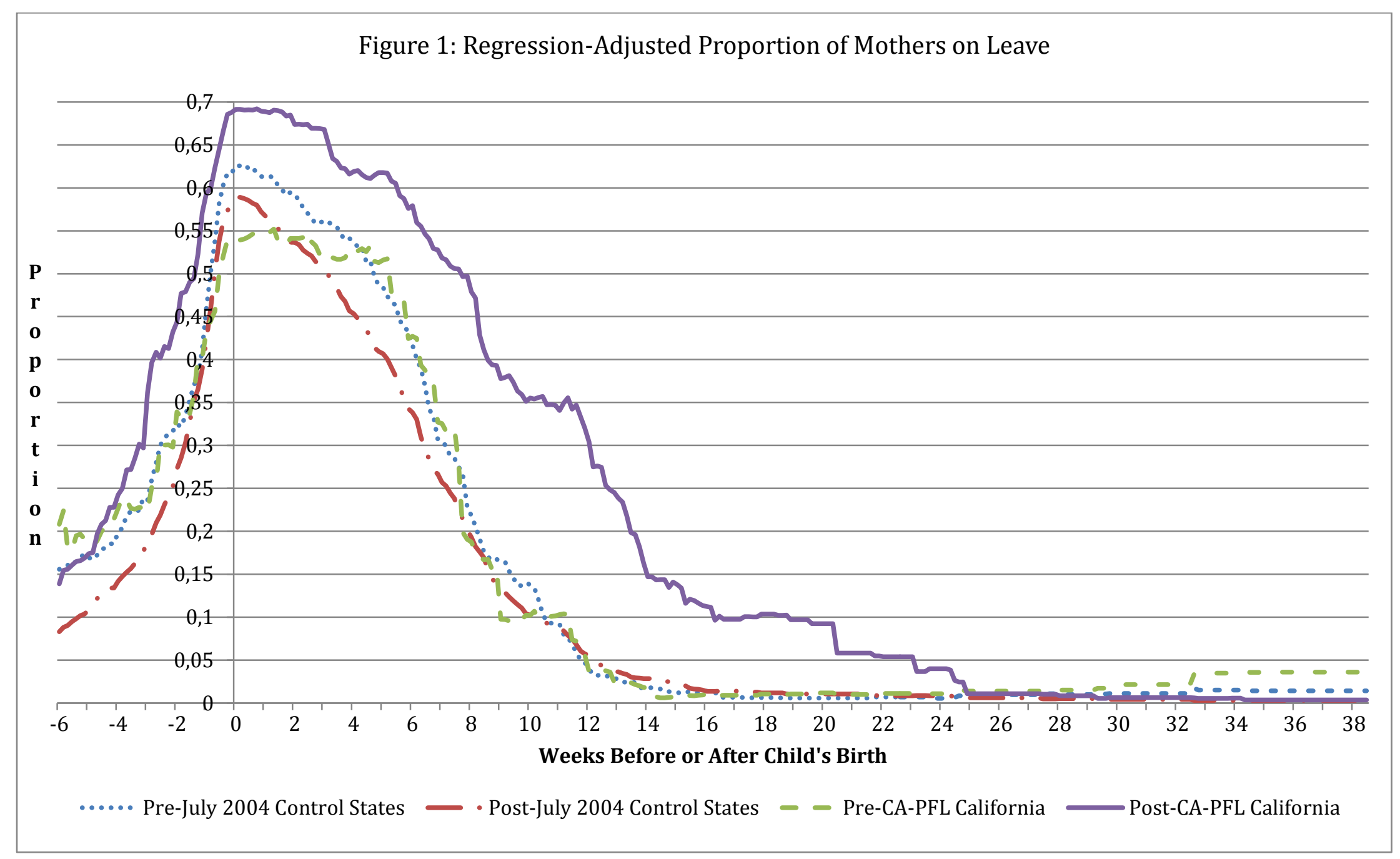




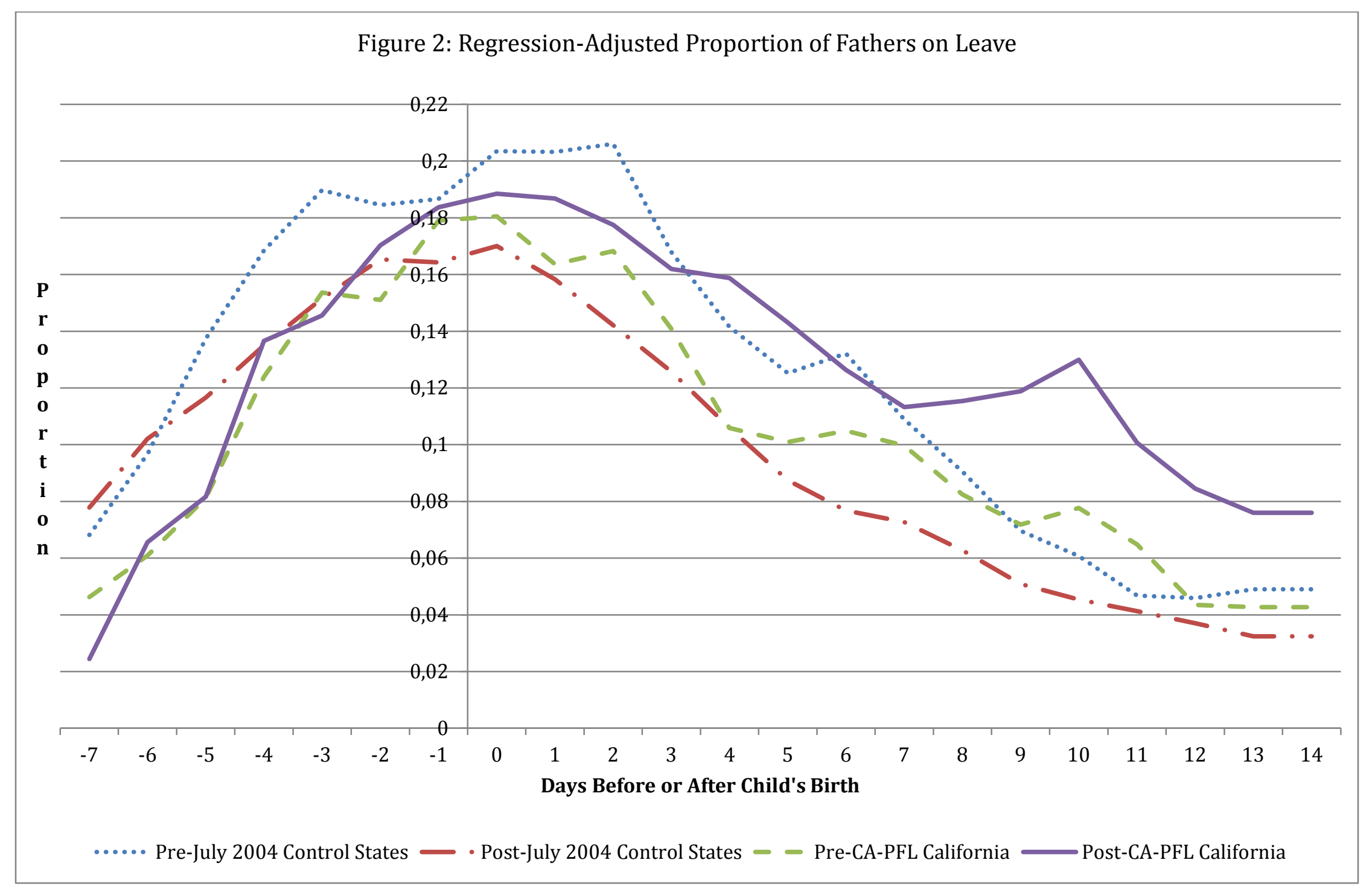




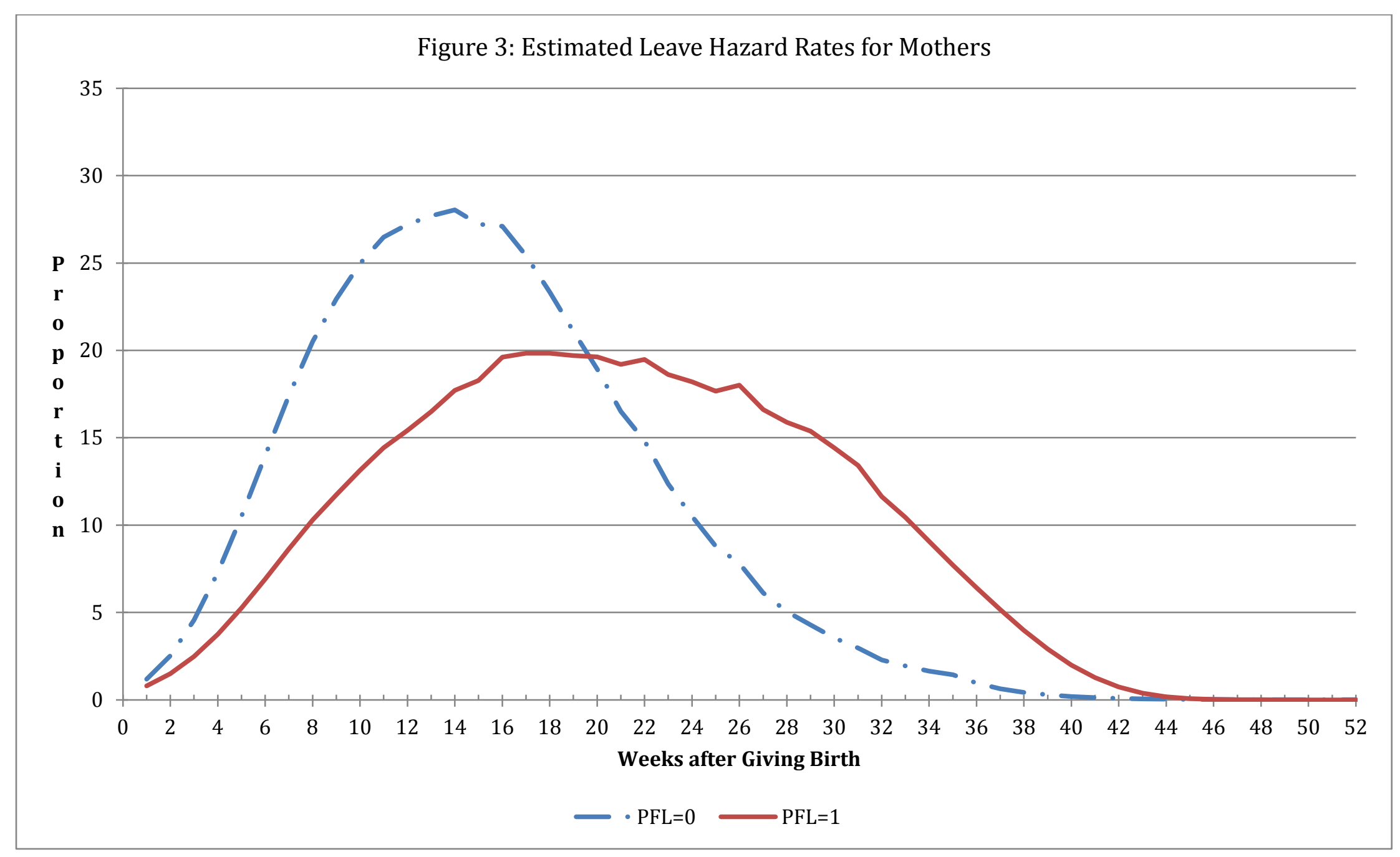




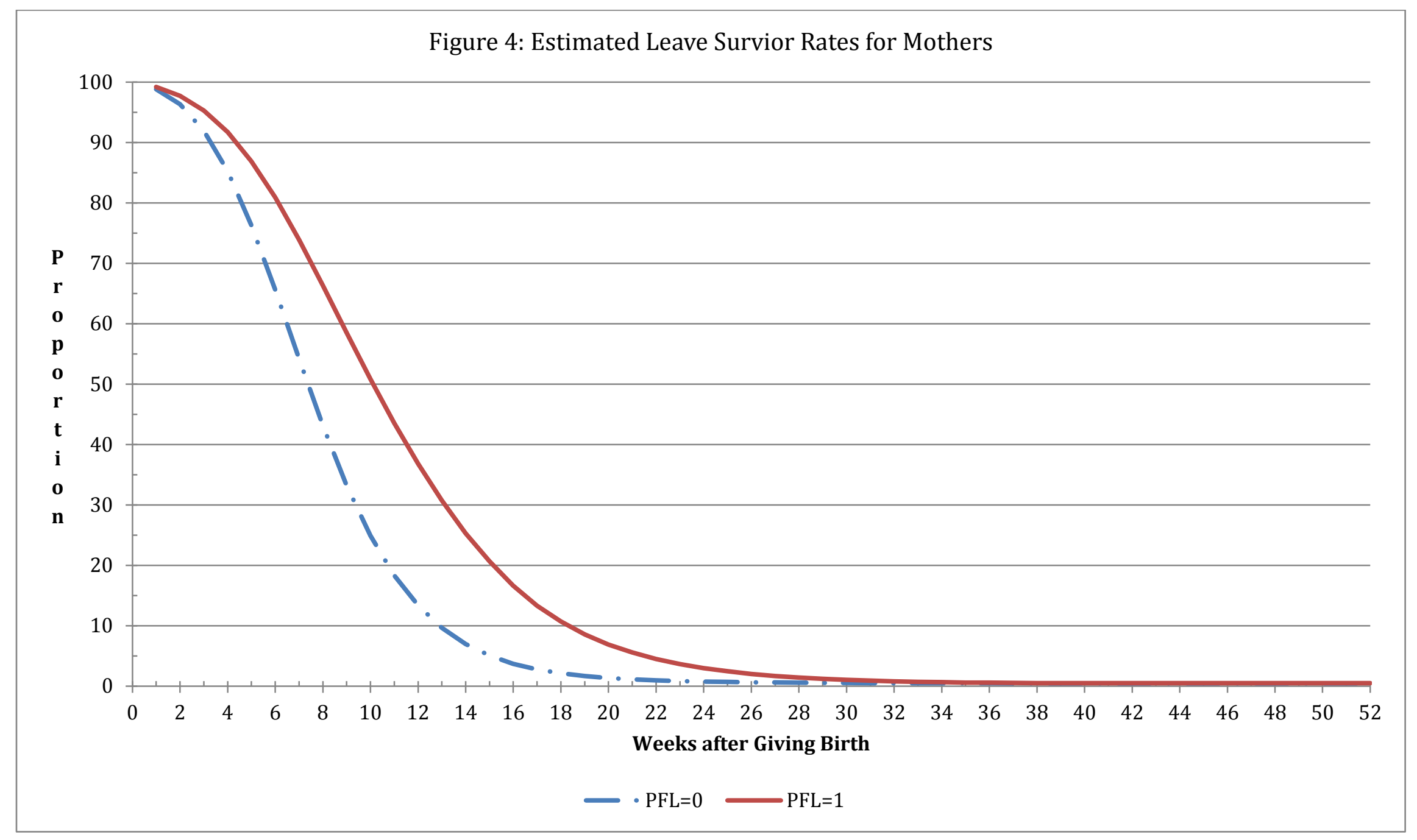




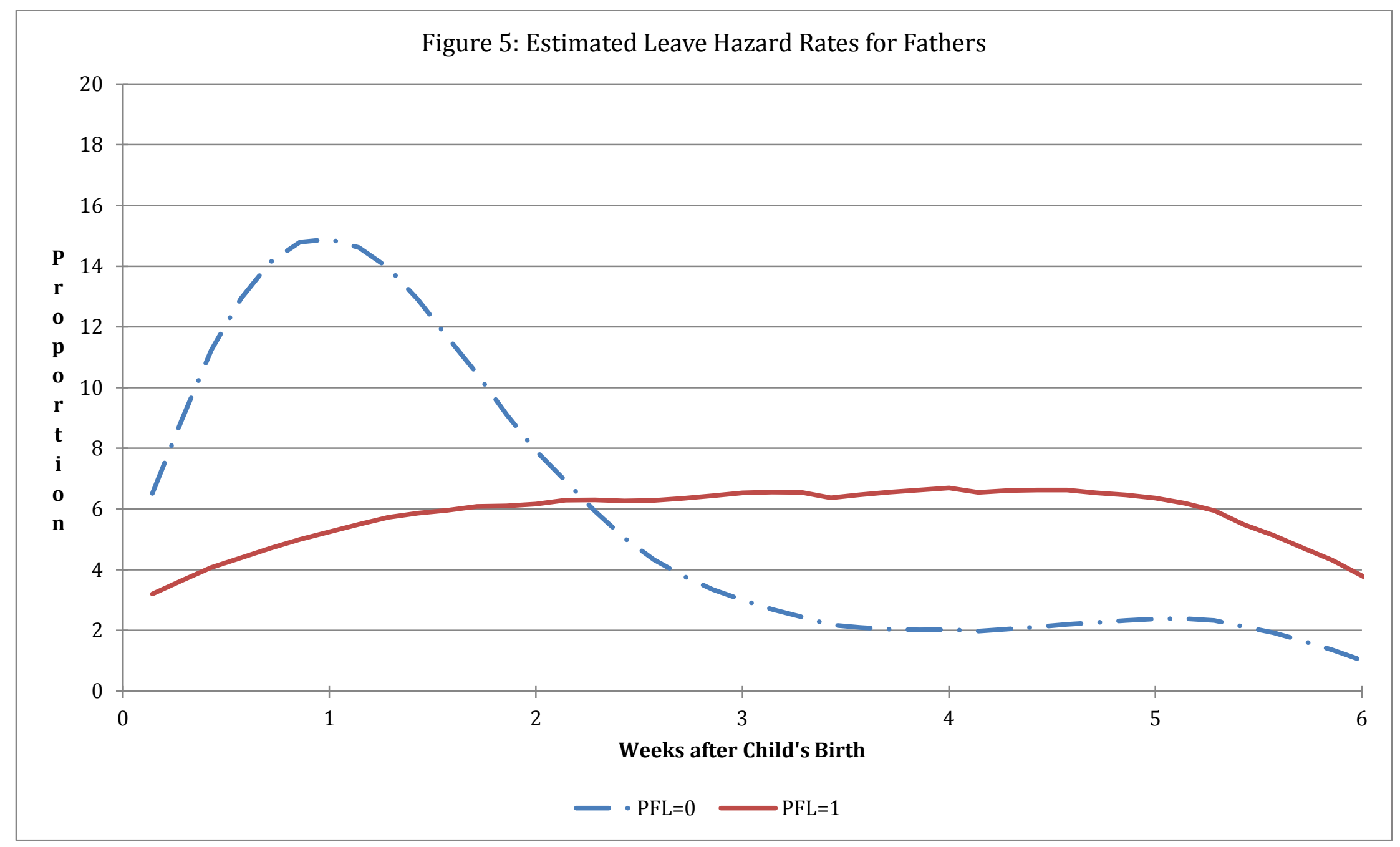




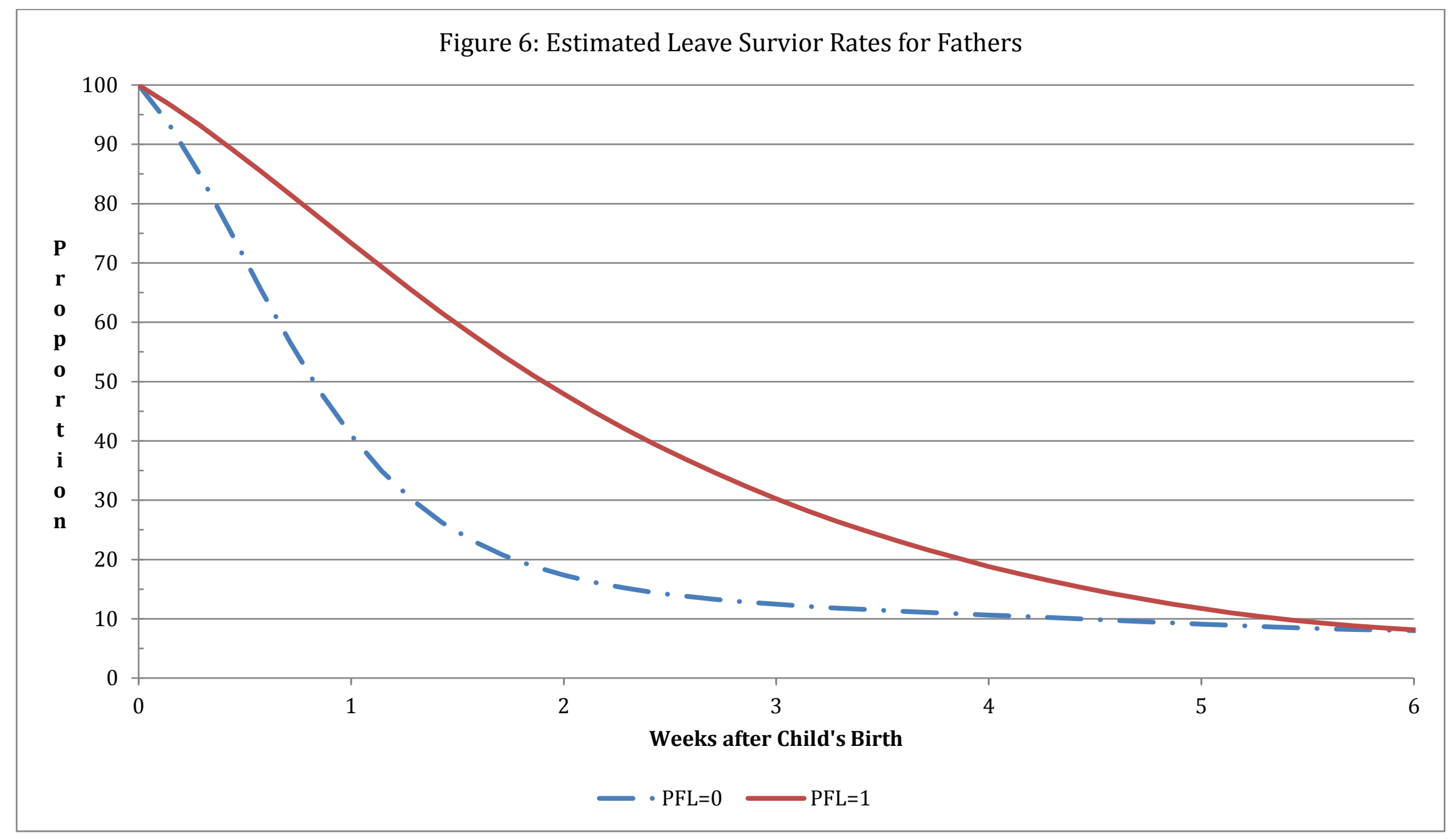




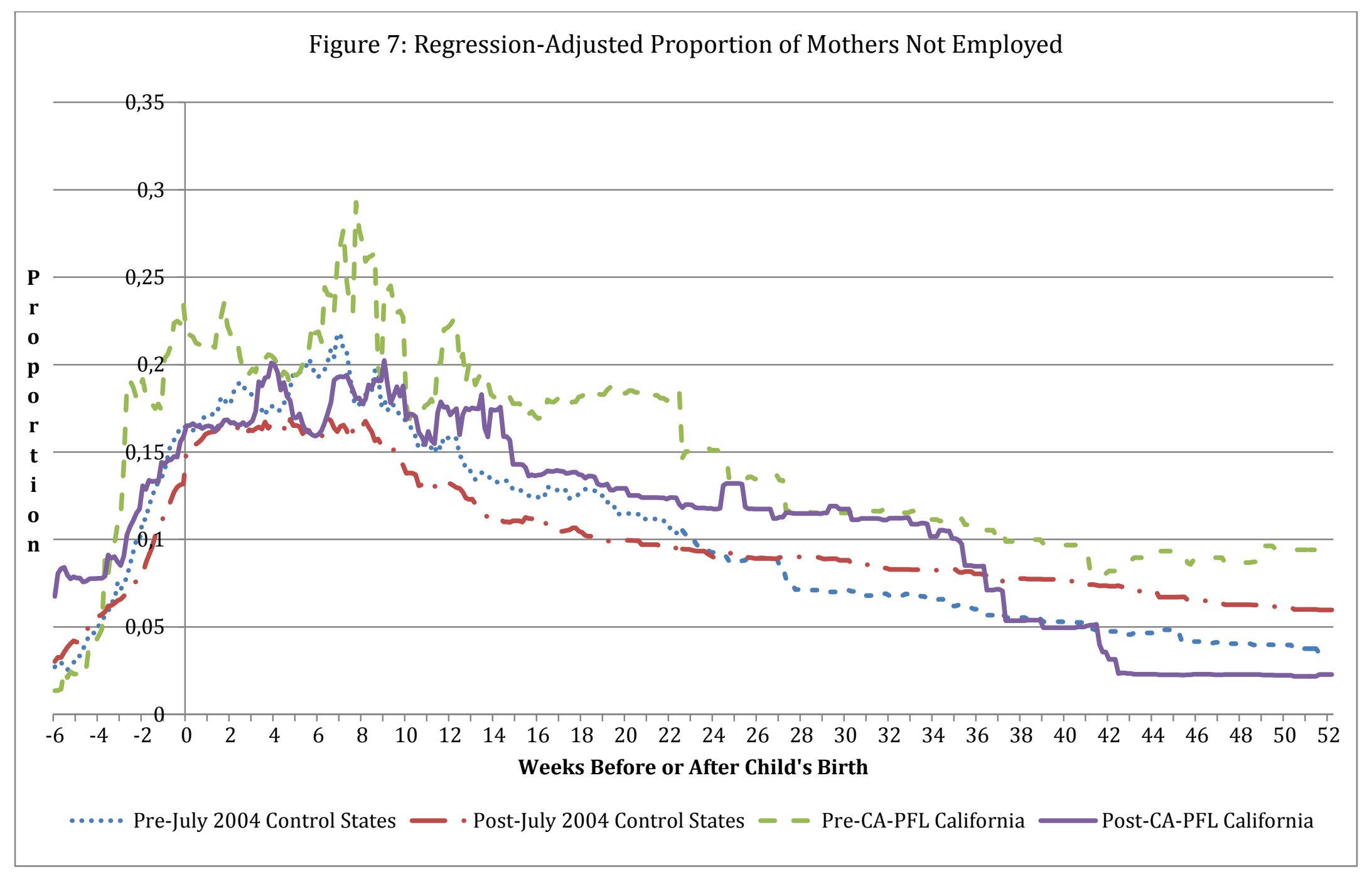




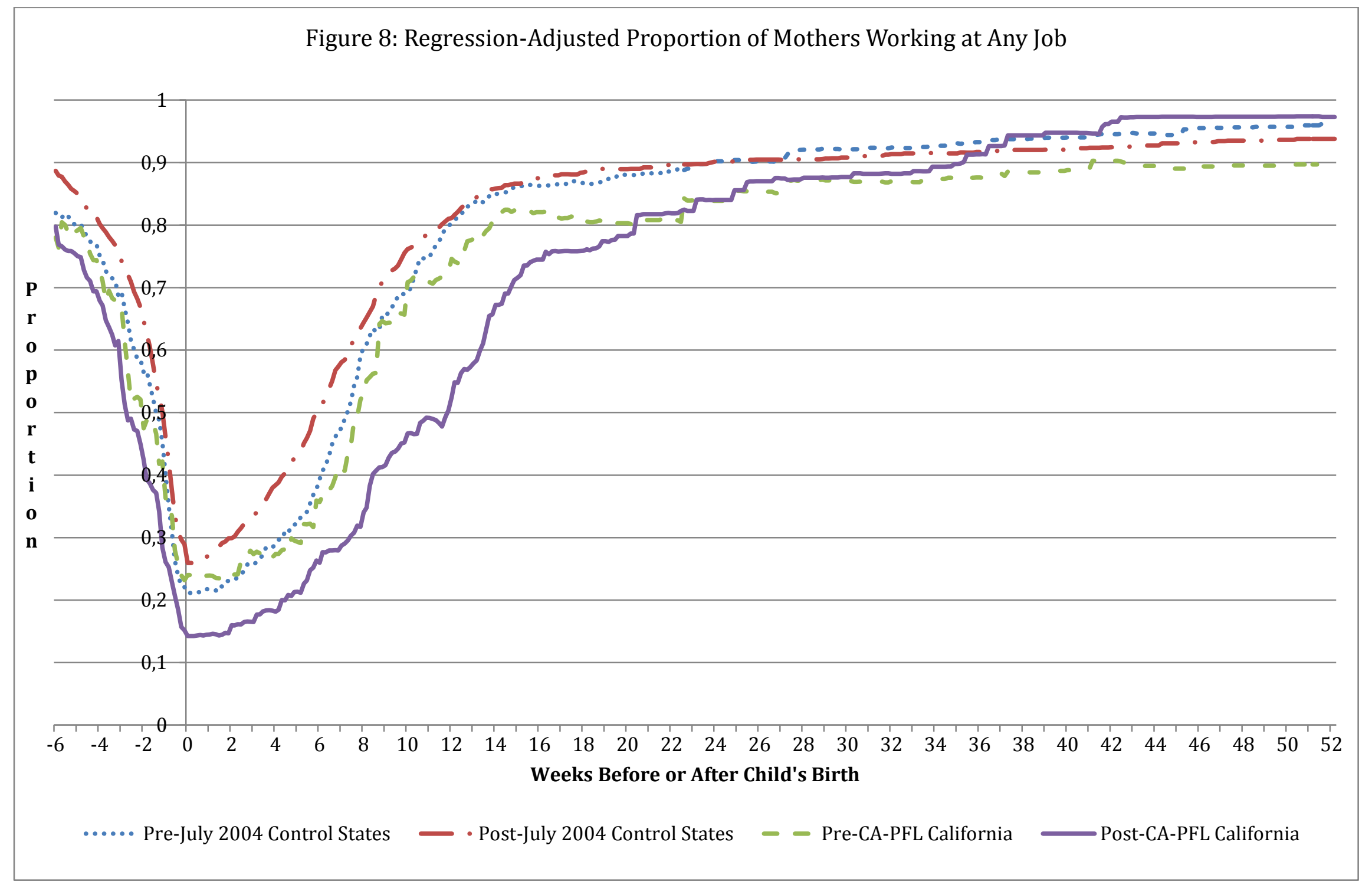




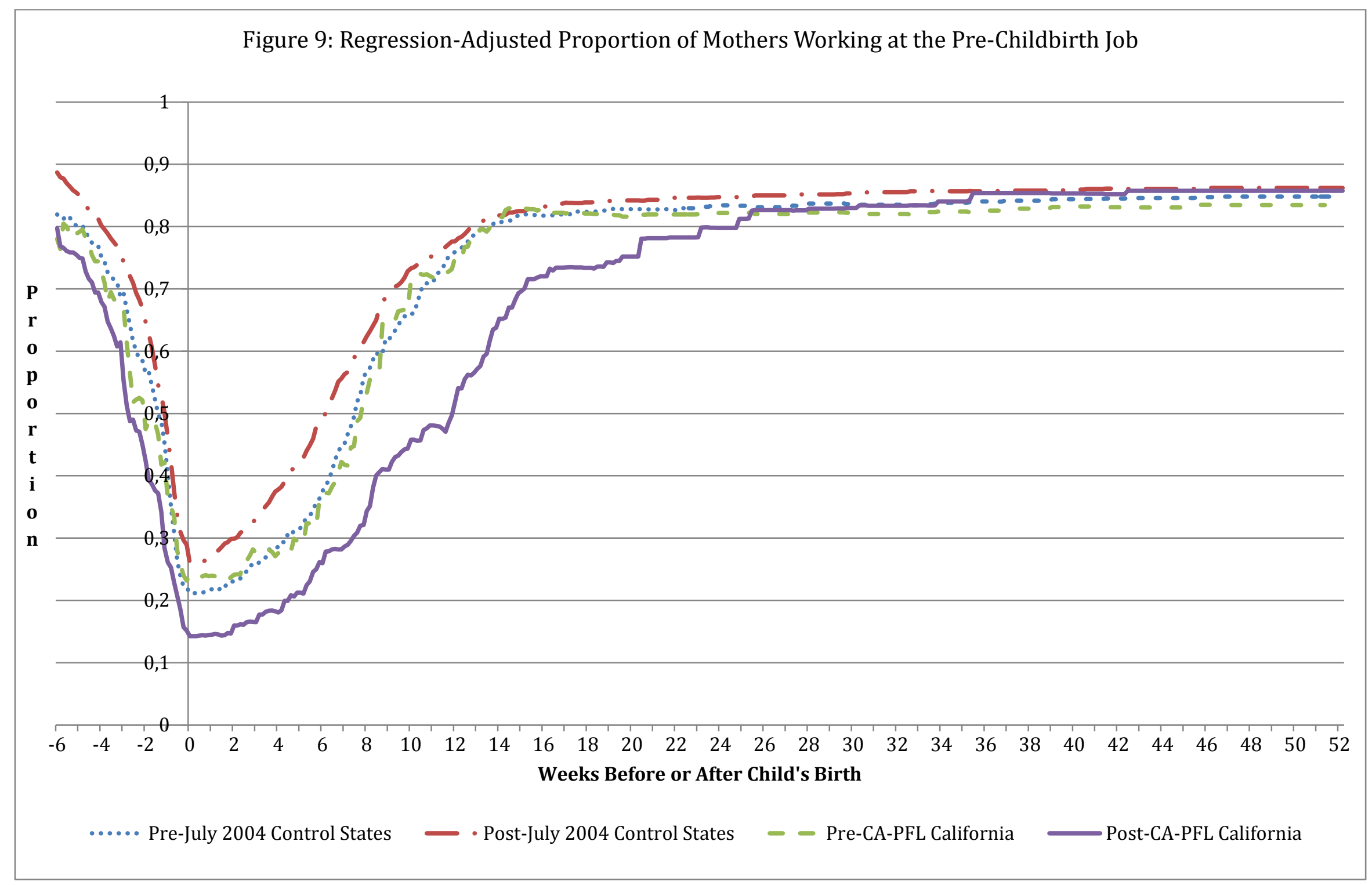


Appendix A: Descriptive Statisics

Appendix Table A.1: Descriptive Statistics for Mothers

\begin{tabular}{lccccccccc}
\hline & \multicolumn{3}{c}{ Control State Mothers } & \multicolumn{4}{c}{ California Mothers } \\
& \multicolumn{3}{c}{ Pre-July 2004} & \multicolumn{2}{c}{ Post-July 2004 } & $\underline{\text { Pre-July 2004 }}$ & $\underline{\text { Post-July 2004 }}$ \\
Black (=1) & 0.183 & $(0.018)$ & 0.180 & $(0.011)$ & 0.050 & $(0.029)$ & 0.058 & $(0.018)$ \\
Hispanic (=1) & 0.111 & $(0.015)$ & 0.100 & $(0.008)$ & 0.608 & $(0.065)$ & 0.462 & $(0.039)$ \\
Age (years) & 19.786 & $(0.078)$ & 23.981 & $(0.070)$ & 19.505 & $(0.216)$ & 24.048 & $(0.179)$ \\
Education (years) & 11.634 & $(0.076)$ & 13.337 & $(0.072)$ & 11.764 & $(0.166)$ & 13.177 & $(0.160)$ \\
Married (=1) & 0.263 & $(0.021)$ & 0.487 & $(0.014)$ & 0.279 & $(0.060)$ & 0.503 & $(0.039)$ \\
Experience (/52) & 3.751 & $(0.082)$ & 7.094 & $(0.076)$ & 2.890 & $(0.194)$ & 6.752 & $(0.203)$ \\
Family Size & 3.547 & $(0.085)$ & 3.051 & $(0.041)$ & 4.224 & $(0.253)$ & 3.671 & $(0.146)$ \\
Child Parity & 1.430 & $(0.031)$ & 1.733 & $(0.026)$ & 1.325 & $(0.082)$ & 1.768 & $(0.069)$ \\
Year-2000 Birth & 0.104 & $(0.014)$ & 0.000 & $(0.000)$ & 0.146 & $(0.047)$ & 0.000 & $(0.000)$ \\
Year-2001 Birth & 0.190 & $(0.018)$ & 0.000 & $(0.000)$ & 0.152 & $(0.048)$ & 0.000 & $(0.000)$ \\
Year-2002 Birth & 0.243 & $(0.020)$ & 0.000 & $(0.000)$ & 0.192 & $(0.053)$ & 0.000 & $(0.000)$ \\
Year-2003 Birth & 0.297 & $(0.022)$ & 0.000 & $(0.000)$ & 0.378 & $(0.065)$ & 0.000 & $(0.000)$ \\
Year-2004 Birth & 0.164 & $(0.017)$ & 0.068 & $(0.007)$ & 0.129 & $(0.045)$ & 0.050 & $(0.017)$ \\
Year-2005 Birth & 0.000 & $(0.000)$ & 0.155 & $(0.010)$ & 0.000 & $(0.000)$ & 0.180 & $(0.030)$ \\
Year-2006 Birth & 0.000 & $(0.000)$ & 0.183 & $(0.011)$ & 0.000 & $(0.000)$ & 0.123 & $(0.026)$ \\
Year-2007 Birth & 0.000 & $(0.000)$ & 0.178 & $(0.011)$ & 0.000 & $(0.000)$ & 0.202 & $(0.031)$ \\
Year-2008 Birth & 0.000 & $(0.000)$ & 0.181 & $(0.011)$ & 0.000 & $(0.000)$ & 0.173 & $(0.030)$ \\
Year-2009 Birth & 0.000 & $(0.000)$ & 0.165 & $(0.011)$ & 0.000 & $(0.000)$ & 0.145 & $(0.028)$ \\
Year-2010 Birth & 0.000 & $(0.000)$ & 0.066 & $(0.007)$ & 0.000 & $(0.000)$ & 0.123 & $(0.026)$ \\
\hline
\end{tabular}

Weighted sample means with standard errors in parentheses. There are 429 pre-July 2004 control mothers, 1,118 post-July 2004 control mothers, 56 pre-July 2004 California mothers, and 159 post-July 2004 California mothers. 
Appendix Table A.2: Descriptive Statistics for Fathers

\begin{tabular}{|c|c|c|c|c|c|c|c|c|}
\hline \multirow[b]{3}{*}{ Black (=1) } & \multicolumn{4}{|c|}{$\underline{\text { Control State Fathers }}$} & \multicolumn{4}{|c|}{$\underline{\text { California Fathers }}$} \\
\hline & \multicolumn{2}{|c|}{$\underline{\text { Pre-July } 2004}$} & \multicolumn{2}{|c|}{ Post-July 2004} & \multicolumn{2}{|c|}{$\underline{\text { Pre-July } 2004}$} & \multicolumn{2}{|c|}{ Post-July 2004} \\
\hline & 0.209 & $(0.020)$ & 0.171 & $(0.011)$ & 0.068 & $(0.035)$ & 0.046 & $(0.017)$ \\
\hline Hispanic (=1) & 0.137 & $(0.017)$ & 0.140 & $(0.010)$ & 0.797 & $(0.056)$ & 0.536 & $(0.041)$ \\
\hline Age (years) & 19.762 & $(0.081)$ & 24.129 & $(0.071)$ & 19.614 & $(0.225)$ & 23.836 & $(0.207)$ \\
\hline Education (years) & 10.994 & $(0.086)$ & 12.403 & $(0.070)$ & 11.595 & $(0.118)$ & 12.922 & $(0.158)$ \\
\hline Married (=1) & 0.207 & $(0.020)$ & 0.470 & $(0.014)$ & 0.288 & $(0.063)$ & 0.448 & $(0.041)$ \\
\hline Experience (/52) & 3.782 & $(0.091)$ & 7.165 & $(0.080)$ & 3.227 & $(0.215)$ & 6.735 & $(0.233)$ \\
\hline Family Size & 3.687 & $(0.085)$ & 3.128 & $(0.044)$ & 5.131 & $(0.315)$ & 4.025 & $(0.164)$ \\
\hline Child Parity & 1.359 & $(0.031)$ & 1.662 & $(0.027)$ & 1.351 & $(0.080)$ & 1.827 & $(0.088)$ \\
\hline Year-2000 Birth & 0.113 & $(0.016)$ & 0.000 & $(0.000)$ & 0.072 & $(0.036)$ & 0.000 & $(0.000)$ \\
\hline Year-2001 Birth & 0.156 & $(0.018)$ & 0.000 & $(0.000)$ & 0.157 & $(0.050)$ & 0.000 & $(0.000)$ \\
\hline Year-2002 Birth & 0.230 & $(0.021)$ & 0.000 & $(0.000)$ & 0.301 & $(0.064)$ & 0.000 & $(0.000)$ \\
\hline Year-2003 Birth & 0.290 & $(0.022)$ & 0.000 & $(0.000)$ & 0.289 & $(0.063)$ & 0.000 & $(0.000)$ \\
\hline Year-2004 Birth & 0.207 & $(0.020)$ & 0.071 & $(0.007)$ & 0.179 & $(0.053)$ & 0.110 & $(0.026)$ \\
\hline Year-2005 Birth & 0.000 & $(0.000)$ & 0.124 & $(0.009)$ & 0.000 & $(0.000)$ & 0.116 & $(0.026)$ \\
\hline Year-2006 Birth & 0.000 & $(0.000)$ & 0.156 & $(0.010)$ & 0.000 & $(0.000)$ & 0.137 & $(0.028)$ \\
\hline Year-2007 Birth & 0.000 & $(0.000)$ & 0.211 & $(0.012)$ & 0.000 & $(0.000)$ & 0.210 & $(0.034)$ \\
\hline Year-2008 Birth & 0.000 & $(0.000)$ & 0.197 & $(0.011)$ & 0.000 & $(0.000)$ & 0.141 & $(0.029)$ \\
\hline Year-2009 Birth & 0.000 & $(0.000)$ & 0.164 & $(0.010)$ & 0.000 & $(0.000)$ & 0.202 & $(0.033)$ \\
\hline Year-2010 Birth & 0.000 & $(0.000)$ & 0.074 & $(0.007)$ & 0.000 & $(0.000)$ & 0.081 & $(0.022)$ \\
\hline
\end{tabular}

Weighted sample means with standard errors in parentheses. There are 391 pre-July 2004 control fathers, 1,142 post-July 2004 control fathers, 52 pre-July 2004 California fathers, and 143 post-July 2004 California fathers. 


\section{Appendix B: Selection of Alternative Control States}

A requirement for the DD procedures to generate consistent estimates of the causal effect of $C A-P F L$ is that the changes over time in the outcomes would have been similar between California and the control states had CA-PFL not been enacted, although the levels could differ. Conversely, if, for example, leave-taking was increasing faster for California mothers than for counterparts, even absent $C A-P F L$, then the program will be spuriously related to increases in leave use, leading to an overestimate of its true causal effect.

While we cannot know what the outcomes during the post-PFL period in California would have been without its implementation, we can observe the pre-program trends. Therefore, one of our empirical strategies is to choose an alternative set of control states with similar trends in maternal leave-taking before July 1, 2004 to those observed in California. Specifically, we use the following procedure to determine whether parents in a given state should be included in the first alternative control group. First, we excluded the 29 states and the District of Columbia with fewer than 8 NLSY-97 women giving birth during the pre-program period, since precision of the estimates would be extremely low in these cases. Second, for each of the remaining 21 states, we estimated the following model, using only observations from before July 1, 2004 for California and the specified state:

$$
Y_{i c t}=\alpha_{0}+\alpha_{1} \boldsymbol{X}_{i c t}+\alpha_{2} T R_{i c t}+\alpha_{3} N O N C A_{i c t}+\alpha_{4} T R \times N O N C A_{i c t}+\varepsilon_{i c t} .
$$

In (B.1), $T R$ is a linear time trend (for the $2000-2004$ period) and NONCA is a dummy variable set to one for the potential control state and zero for California. The interaction term, $T R \times N O N C A_{i c t}$, allows the leave-taking time trend to differ between California and the other state, and we treat that state as a possible control if we are unable to reject the null hypothesis that $\hat{\alpha}_{4}$ equals zero. Although similar numbers of NLSY-97 fathers and mothers have children before July 2004, too few fathers 
take leave to identify valid control states using this approach, and so we used the same states as those identified as the control group for mothers.

Appendix Table B.1 presents $\hat{\alpha}_{4}$ from equation (B.1) for each potential alternative control state, the associated standard error, the number of pre-July 2004 births to mothers, and whether each state was included in the alternative control group. In addition to eliminating those states with statistically different time trend coefficients, we exclude six states (AL, DE, MS, MO, TN, and WI) whose time trend coefficients are not statistically different but exceed 1.0 in absolute value. Although admittedly arbitrary, we consider the pre-trend patterns in these states to be too different from those in California to provide valid controls. Ultimately, 15 states were deemed to be valid controls for mothers using this approach. The other 35 states and District of Columbia either had different pre-PFL trends in leave-taking or provided too few observations to be compared with California.

In a second approach we identify a comparison group using a variant of the methodology introduced by Abadie, Diamond, and Hainmueller (2010). The Abadie et al. procedure creates a synthetic control state for a treatment state using a weighted combination of other available states, again based on pre-treatment trends. This approach is designed for use with aggregate data (e.g., data aggregated at the state level), so we first take our individual-level NLSY data and aggregate to the state level. Next, we use Abadie et al.'s procedure to create a synthetic control state for California based on leave-taking from 2000 to July 2004. The synthetic California control state generated by this procedure is comprised of observations from Georgia (weighted by 0.526), Illinois (weighted at 0.334), and Texas (weighted at 0.101). We take these weights (with a weight of 1.000 for California) and apply them to our individual-level NLSY data. In particular, we re-estimate the 
models including observations from California, Georgia, Illinois, and Texas with the NLSY sampling weights adjusted by the Abadie weights reported above.

Appendix Table B.1: Results from Regressions to Select Alternative Control States

\begin{tabular}{cccccc}
\hline STATE & $\begin{array}{c}\text { Number of } \\
\text { Pre-July 2004 } \\
\text { Births to } \\
\text { Mothers }\end{array}$ & $\begin{array}{c}\text { Time-Trend } \\
\text { Coefficient }\end{array}$ & $\begin{array}{c}\text { Standard } \\
\text { Error }\end{array}$ & $\begin{array}{c}\text { T- } \\
\text { Statistic }\end{array}$ & $\begin{array}{c}\text { Included as } \\
\text { Control } \\
\text { State }\end{array}$ \\
\hline AL & 8 & -1.284 & 1.192 & 1.08 & No \\
AZ & 14 & -0.531 & 0.532 & 1.00 & Yes \\
CA & 56 & N/A & N/A & N/A & Yes \\
DE & 9 & -1.221 & 0.937 & 1.30 & No \\
FL & 13 & -0.828 & 0.853 & 0.97 & Yes \\
GA & 10 & 0.206 & 0.676 & 0.30 & Yes \\
IL & 20 & -0.550 & 0.445 & 1.24 & Yes \\
IN & 12 & -0.175 & 0.550 & 0.32 & Yes \\
MD & 10 & -0.657 & 0.670 & 0.98 & Yes \\
MI & 15 & 0.401 & 0.671 & 060 & Yes \\
MN & 16 & -0.733 & 0.521 & 1.41 & Yes \\
MS & 10 & -1.276 & 1.083 & 1.18 & No \\
MO & 11 & -1.980 & 1.029 & 1.92 & No \\
NY & 31 & 0.380 & 0.454 & 0.84 & Yes \\
NC & 32 & 0.600 & 0.459 & 1.31 & Yes \\
OH & 13 & -0.046 & 0.775 & 0.06 & Yes \\
PA & 14 & -0.199 & 0.631 & 0.32 & Yes \\
TN & 13 & -1.069 & 1.110 & 0.96 & No \\
TX & 64 & -0.513 & 0.359 & 1.43 & Yes \\
VA & 28 & -0.243 & 0.468 & 0.52 & Yes \\
WI & 8 & 1.369 & 1.132 & 1.21 & No \\
\hline
\end{tabular}

The time-trend interaction measures the difference in the 2000 to pre-July 2004 time trend between California and each state listed. States with fewer than 8 pre-July 2004 births to mothers are not considered as control states These include (with the number of births shown in parentheses): AK (1); AR (4); CO (4); CT (2); DC (1); HI (0); ID (0); IA (0); KS (4); KY (6); LA (7); ME (0); MA (7); MT (3); NE (1); NV (3); NH (0); NJ (5); NM (2); ND (5); OK (5); OR (4); RI (1); SC (6); SD (3); UT (0); VT (5); WA (3); WV (0); and WY (0). The text provides further criteria for whether other states are included in the control group. 